FEDERAL RESERVE BANK OF SAN FRANCISCO

WORKING PAPER SERIES

\title{
House Prices, Expectations, and Time-Varying
} Fundamentals

\author{
Paolo Gelain \\ Norges Bank \\ Kevin J. Lansing \\ Federal Reserve Bank of San Francisco
}

May 2014

Working Paper 2013-03

http://www.frbsf.org/publications/economics/papers/2013/wp2013-03.pdf

The views in this paper are solely the responsibility of the authors and should not be interpreted as reflecting the views of the Federal Reserve Bank of San Francisco or the Board of Governors of the Federal Reserve System. 


\title{
House Prices, Expectations, and Time-Varying Fundamentals*
}

\author{
Paolo Gelain ${ }^{\dagger}$ \\ Norges Bank
}

\author{
Kevin J. Lansing ${ }^{\ddagger}$ \\ Federal Reserve Bank of San Francisco
}

May 7, 2014

\begin{abstract}
We investigate the behavior of the equilibrium price-rent ratio for housing in a standard asset pricing model and compare the model predictions to survey evidence on the return expectations of real-world housing investors. We allow for time-varying risk aversion (via external habit formation) and time-varying persistence and volatility in the stochastic process for rent growth, consistent with U.S. data for the period 1960 to 2013. Under fully-rational expectations, the model significantly underpredicts the volatility of the U.S. price-rent ratio for reasonable levels of risk aversion. We demonstrate that the model can approximately match the volatility of the price-rent ratio in the data if near-rational agents continually update their estimates for the mean, persistence and volatility of fundamental rent growth using only recent data (i.e., the past 4 years), or if agents employ a simple moving-average forecast rule for the price-rent ratio that places a large weight on the most recent observation. These two versions of the model can be distinguished by their predictions for the correlation between expected future returns on housing and the pricerent ratio. Only the moving-average model predicts a positive correlation such that agents tend to expect high future returns when prices are high relative to fundamentals - a feature that is consistent with a wide variety of survey evidence from real estate and stock markets.
\end{abstract}

Keywords: Asset pricing, Excess volatility, Housing bubbles, Predictability, Time-varying risk premiums, Expected returns.

JEL Classification: D84, E32, E44, G12, O40, R31.

\footnotetext{
${ }^{*}$ Forthcoming, Journal of Empirical Finance. For helpful comments and suggestions, we would like to thank colleagues at the Norges Bank, Lars Løchstøer, Tassos Malliaris, and seminar participants at Carleton University, the 2012 Meeting of the Society for Computational Economics, the 2012 Symposium of the Society for Nonlinear Dynamics and Econometrics, the 2012 Meeting of the European Economics Association, the 2013 Meeting of the American Economics Association, the 2013 Arne Ryde Workshop in Financial Economics hosted by Lund University, and the 2013 BMRC-QASS Conference on Macro and Financial Economics, hosted by the Brunel Macroeconomics Research Centre. We would also like to thank two anonymous referees for comments that significantly improved the paper. Part of this research was conducted while Lansing was a visiting economist at the Norges Bank, whose hospitality is gratefully acknowledged.

${ }^{\dagger}$ Norges Bank, P.O. Box 1179, Sentrum, 0107 Oslo, email: paolo.gelain@norges-bank.no

${ }^{\ddagger}$ Corresponding author. Federal Reserve Bank of San Francisco, P.O. Box 7702, San Francisco, CA 941207702, email: kevin.j.lansing@sf.frb.org
} 


\section{Introduction}

\subsection{Overview}

House prices in the United States increased dramatically in the years prior to 2007. During the boom years, many economists and policymakers argued that a bubble did not exist and that numerous fundamental factors were driving the run-up in prices. ${ }^{1}$ But in retrospect, many studies now attribute the run-up to a classic bubble driven by over-optimistic projections about future house price growth which, in turn, led to a collapse in lending standards. ${ }^{2}$ Reminiscent of the U.S. stock market mania of the late-1990s, the mid-2000s housing market was characterized by an influx of unsophisticated buyers and record transaction volume. When the optimistic house price projections eventually failed to materialize, the bubble burst, setting off a chain of events that led to a financial and economic crisis. The "Great Recession," which started in December 2007 and ended in June 2009, was the most severe economic contraction since 1947, as measured by the peak-to-trough decline in real GDP (Lansing 2011).

This paper investigates the behavior of the equilibrium price-rent ratio for housing in a standard Lucas-type asset pricing model and compares the model predictions to survey evidence on the return expectations of real-world housing investors. We allow for time-varying risk aversion (via external habit formation) and time-varying persistence and volatility in the stochastic process for rent growth, consistent with U.S. data for the period 1960 to 2013. Under fully-rational expectations, the model significantly underpredicts the volatility of the U.S. price-rent ratio for reasonable levels of risk aversion. We demonstrate that the model can approximately match the volatility of the price-rent ratio in the data if near-rational agents continually update their estimates for the mean, persistence and volatility of fundamental rent growth using only recent data (i.e., the past 4 years), or if agents employ a simple movingaverage forecast rule for the price-rent ratio that places a large weight on the most recent observation. These two versions of the model can be distinguished by their predictions for the correlation between expected future returns on housing and the price-rent ratio. Only the moving-average model predicts a positive correlation such that agents tend to expect high future returns when prices are high relative to fundamentals - a feature that is consistent with a wide variety of survey evidence from real estate and stock markets. ${ }^{3}$

\footnotetext{
${ }^{1}$ See, for example, McCarthy and Peach (2004) and Himmelberg, et al. (2005). In an October 2004 speech, Fed Chairman Alan Greenspan (2004) argued that there were "significant impediments to speculative trading" in the housing market that served as "an important restraint on the development of price bubbles." In a July 1, 2005 media interview, Ben Bernanke, then Chairman of the President's Council of Economic Advisers, asserted that fundamental factors such as strong growth in jobs and incomes, low mortgage rates, demographics, and restricted supply were supporting U.S. house prices. In the same interview, Bernanke stated his view that a substantial nationwide decline in house prices was "a pretty unlikely possibility." For additional details, see Jurgilas and Lansing (2013).

${ }^{2}$ For a comprehensive review of events, see the report of the U.S. Financial Crisis Inquiry Commission (2011). Recently, in a review of the Fed's forecasting record leading up to the crisis, Potter (2011) acknowledges a "misunderstanding of the housing boom... [which] downplayed the risk of a substantial fall in house prices."

${ }^{3}$ The survey evidence on expected returns is discussed in more detail in the next section. For an overview the evidence, see Williams (2013).
} 
As part of our quantitative analysis, we apply the Campbell and Shiller (1988) log-linear approximation of the return identity to the housing market. According to this identity, the variance of the log price-rent ratio must equal the sum of the ratio's covariances with: (1) future rent growth rates, and (2) future realized housing returns. The magnitude of each covariance term is a measure of the predictability of future rent growth or future realized returns when the current price-rent ratio is employed as the sole regressor in a forecasting equation. As in the U.S. data, the moving-average model exhibits the property that a higher price-rent ratio in the current period strongly predicts lower realized returns in the future, but the predictive power for future rent growth is very weak. Interestingly, even though a higher price-rent ratio in the data predicts lower realized returns, the survey evidence shows that real-world investors fail to take this relationship into account; instead they continue to forecast high future returns following a sustained run-up in the price-rent ratio. Such behavior is consistent with a moving-average forecast rule but is inconsistent with the fully-rational and near-rational versions of the model.

We also show that the moving-average model can deliver either a positive or negative regression coefficient on the price-rent ratio when the ratio is used to predict future rent growth. The sign of the regression coefficient is influenced by the value of a utility curvature parameter. Our simulation results can therefore help account for the empirical findings of Engsted and Pedersen (2012), who document significant cross-country and sub-sample instability in the sign of this regression coefficient using housing market data from 18 OECD countries over the period 1970 to 2011.

An additional contribution of the paper is to derive an approximate analytical solution for the fully-rational house price in the case when fundamental rent growth exhibits time-varying persistence and volatility. Our specification for rent growth employs the bilinear time series model originally developed Granger and Andersen (1978) which allows for nonlinear behavior within a continuous state space. Our solution procedure makes use of a change of variables to preserve as much of the model's nonlinear characteristics as possible.

Standard dynamic stochastic general-equilibrium (DSGE) models with fully-rational expectations have difficulty producing large swings in house prices that resemble the patterns observed in the U.S. and other countries over the past decade. Indeed, it is common for such models to postulate extremely large and persistent exogenous shocks to rational agents' preferences for housing in an effort to bridge the gap between the model and the data. ${ }^{4}$ Leaving aside questions about where these preference shocks actually come from and how agents' responses to them could become coordinated, we demonstrate numerically that an upward shift in the representative agent's preference for housing raises the mean price-rent ratio under all three expectations regimes. At the same time, the preference shift lowers the average realized return on housing. Under rational expectations, the agent will take this relationship into account when forecasting such that the conditional expected future return on housing will move

\footnotetext{
${ }^{4}$ See for example, Iacoviello and Neri (2010), among others.
} 
in the opposite direction as the price-rent ratio in response to a shift in housing preferences. Hence, while a fully-rational model with housing preference shocks could potentially match the volatility of the price-rent ratio in the data, such a model would still predict a negative correlation between the expected future return on housing and the price-rent ratio- directly at odds with the survey evidence to be described in section 2. Moreover, since preference shocks influence the utility dividend, or "imputed rent" received from housing, a preference-driven run-up in house prices would be accompanied by an increase in the imputed rent-something which is not observed in U.S. data during the boom years of the mid-2000s.

\subsection{Related Literature}

Numerous empirical studies starting with Shiller (1981) and LeRoy and Porter (1981) have shown that stock prices appear to exhibit excess volatility when compared to the discounted stream of ex post realized dividends. ${ }^{5}$ Similarly, Campbell, et al. (2009) find that movements in U.S. house price-rent ratios cannot be fully explained by movements in subsequent rent growth.

A large body of research seeks to explain asset price behavior using some type of distorted belief mechanism or misspecified forecast rule in a representative agent framework. Examples along these lines include Barsky and Delong (1993), Timmerman (1996), Barberis, Shleifer, and Vishney (1998), Lansing (2006, 2010), Adam, Marcet, and Nicolini (2008), Branch and Evans (2010), Fuster, et al. (2012), and Hommes and Zhu (2014), among others.

An empirical study by Chow (1989) finds that an asset pricing model with adaptive expectations outperforms one with rational expectations in accounting for observed movements in U.S. stock prices and interest rates. Huh and Lansing (2000) show that a model with backwardlooking expectations is better able to capture the temporary rise in long-term nominal interest rates observed in U.S. data at the start of the Volcker disinflation in the early-1980s. Some recent research that incorporates moving-average forecast rules or adaptive expectations into otherwise standard models include Sargent (1999, Chapter 6), Evans and Ramey (2006), Lansing (2009), and Huang, et. al (2009), among others. Huang, et al. (2009) state that "adaptive expectations can be an important source of frictions that amplify and propagate technology shocks and seem promising for generating plausible labor market dynamics."

Coibion and Gorodnichencko (2012) find robust evidence against full-information rational expectations in survey forecasts for U.S. inflation and unemployment. Using an estimated New Keynesian DSGE model, Levine, et al. (2012) find that the fraction of agents who employ a moving-average type forecast rule lies in the range of 0.65 to 0.83 . Gelain, et al. (2013) show that the introduction of simple moving-average forecast rules for a subset of agents can significantly magnify the volatility and persistence of house prices and household debt in a standard DSGE model with housing. Granziera and Kozicki (2012) show that a simple Lucastype asset pricing model with backward-looking, extrapolative-type expectations can roughly

\footnotetext{
${ }^{5}$ Lansing and LeRoy (2014) provide a recent update on this literature.
} 
match the run-up in U.S. house prices from 2000 to 2006 as well as the subsequent sharp downturn.

Constant-gain learning algorithms of the type described by Evans and Honkapoja (2001) are similar in many respects to moving-average expectations; both formulations assume that agents apply exponentially-declining weights to past data when constructing forecasts of future variables. Adam, et al. (2012) show that the introduction of constant-gain learning can help account for recent cross-country patterns in house prices and current account dynamics. In contrast to our setup, their model assumes the presence of volatile and persistent exogenous shocks to the representative agent's preference for housing services, a feature that helps their model to fit the data. A strength of their model is that it takes into account the positive supply response of residential construction to rising house prices - a feature that is evident in most historical real estate booms (Shiller 2008). When the new housing supply becomes available with a lag, it can reinforce an expectation-driven decline in house prices.

There is also a large literature on "rational bubbles" in which agents are fully cognizant of the fundamental asset price, but nevertheless are willing to pay more than this amount. This can occur if expectations of future price appreciation are large enough to satisfy the rational agent's required rate of return. ${ }^{6}$ A drawback of rational bubble models is the prediction that the equilibrium price-dividend ratio (or price-rent ratio) has a unit root. A more elaborate version assumes that the rational bubble will periodically crash according to some universallyknown probability function (Evans 1991), but this is an ad hoc feature that is determined completely outside of the model. Recently, Doblas-Madrid (2012) develops a model with only rational agents who ride bubbles while optimally weighing potential profits if they can successfully time the market versus the potential losses if the bubble bursts before they can sell. In his model, price run-ups relative to fundamentals can coincide with the speculators' rational expectations of higher future profits for an extended period, a feature which is consistent with the survey evidence.

\section{Evidence on Investor Expectations}

The fundamental value of an asset is typically measured by the present-value of expected future cash or service flows that will accrue to the owner. Service flows from housing are called "imputed rents." The discount rate used in the present-value calculation is comprised of a risk-free yield and a compensation for perceived risk, i.e., a risk premium. Their sum defines the rate of return that an investor expects to receive to justify purchase of the asset. All else equal, a lower risk premium implies a lower expected return and a lower discount rate in the present-value calculation. Future service flows will be discounted less and the fundamental value will rise.

\footnotetext{
${ }^{6}$ Lansing (2010) derives a continuum of rational bubble solutions in a standard Lucas-type asset pricing model.
} 
Making use of the above logic, Cochrane (2011) argues that one cannot easily tell the difference between a bubble and a situation where rational investors have low risk premia, implying lower expected returns on the risky asset. Specifically, he remarks "Crying bubble is empty unless you have an operational procedure for distinguishing them from rationally low risk premiums." Along similar lines, Favilukis, et al. (2013) argue that the run-up in U.S. house prices relative to rents was largely due to a financial market liberalization (easier lending standards and lower mortgage transaction costs) that reduced buyers' perceptions of the riskiness of housing assets. In the words of the authors, "a financial market liberalization drives price-rent ratios up because it drives risk premia down... Procyclical increases in [fundamental] price-rent ratios reflect rational expectations of lower future returns."

In our view, the relaxation of lending standards in the mid-2000s was an endogenous consequence of the house price run-up, not an exogenous fundamental driver of the runup. Standards were relaxed because lenders (and willing borrowers) expected house price appreciation to continue indefinitely. Empirical evidence supports this view. Within the United States, past house price appreciation in a given area had a significant positive influence on subsequent loan approval rates in the same area (Dell'Ariccia, et al. 2012, Goetzmann, et al. 2012).

One way in which a bubble might be distinguished from a situation with rationally low risk premiums is to examine investors' expectations about future returns on the asset. Rational investors with low risk premiums would expect low future returns after a sustained price run-up, whereas irrationally exuberant investors in the midst of a bubble would expect high future returns because they simply extrapolate recent price action into the future. Survey data from both real estate and stock markets show that real-world investors typically expect high future returns near market peaks, not low future returns. Overall, the survey evidence directly contradicts the view that declining risk premiums (resulting in low expected returns) were the explanation for the run-up in U.S. house prices relative to rents.

In a study of data from the Michigan Survey of Consumers, Piazzesi and Schneider (2009) report that "starting in 2004, more and more households became optimistic after having watched house prices increase for several years." In a review of the time series evidence on housing investor expectations from 2002 to 2008, Case, Shiller, and Thompson (2012) conclude (p. 282) that "1-year expectations [of future house prices changes] are fairly well described as attenuated versions of lagged actual 1-year price changes."

Anecdotal evidence further supports the view that U.S. housing investors had high expected returns near the market peak. The June 6, 2005 cover of Fortune magazine was titled "Real Estate Gold Rush-Inside the hot-money world of housing speculators, condo-flippers and get-rich-quick schemers." One week later, the June 13, 2005 cover of Time magazine was titled "Home \$weet Home - Why we're going gaga over real estate." Both covers depicted happy and celebrating housing investors - all suggesting a rosy outlook for U.S. real estate.

With regard to the stock market, studies by Fischer and Statman (2002), Vissing-Jorgenson 


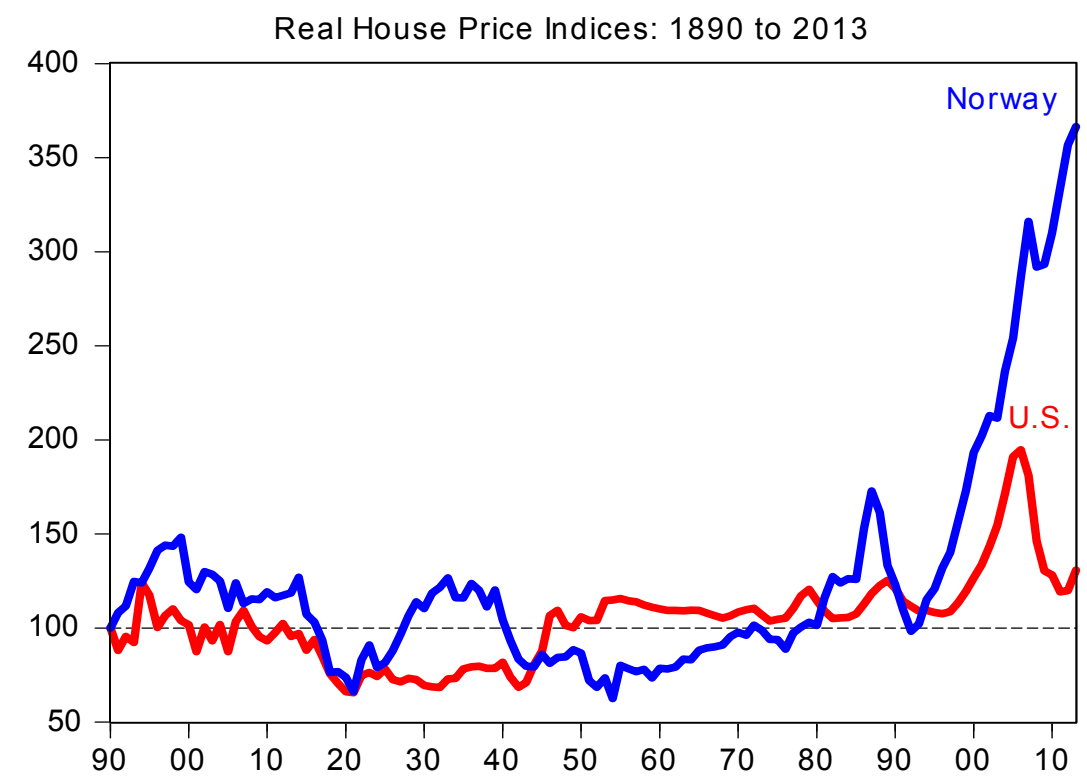

Figure 1: Long-run real house price indices for U.S. and Norway. Periods of stagnant real house prices are interspersed with booms and busts. Norway experienced a major housing price boom in the late 1980s followed by a crash in the early 1990s. The earlier boom-bust pattern in Norway is similar in magnitude to the recent boom-bust pattern in U.S. house prices. Real house prices are indexed to 100 in 1890.

(2004) and Amromin and Sharpe (2014) all find evidence of extrapolative or procyclical expected returns among investors. Recently, in a comprehensive study of the expectations of U.S. stock market investors using survey data from a variety of sources, Greenwood and Shleifer (2013) find that measures of investor expectations about future stock returns are positively correlated with (1) the price-dividend ratio, (2) past stock returns, and (3) investor inflows into mutual funds. They conclude (p. 30) that "[O]ur evidence rules out rational expectations models in which changes in market valuations are driven by the required returns of a representative investor...Future models of stock market fluctuations should embrace the large fraction of investors whose expectations are extrapolative." We apply their advice here to a model of housing market fluctuations.

\section{Housing Market Data}

Figure 1 plots real house price indices in the U.S. and Norway from 1890 to 2013. The U.S. data are updated from Shiller (2005) while data for Norway are updated from Eitrheim and Erlandsen $(2004,2005)$. Both series show that real house prices were relatively stagnant for 


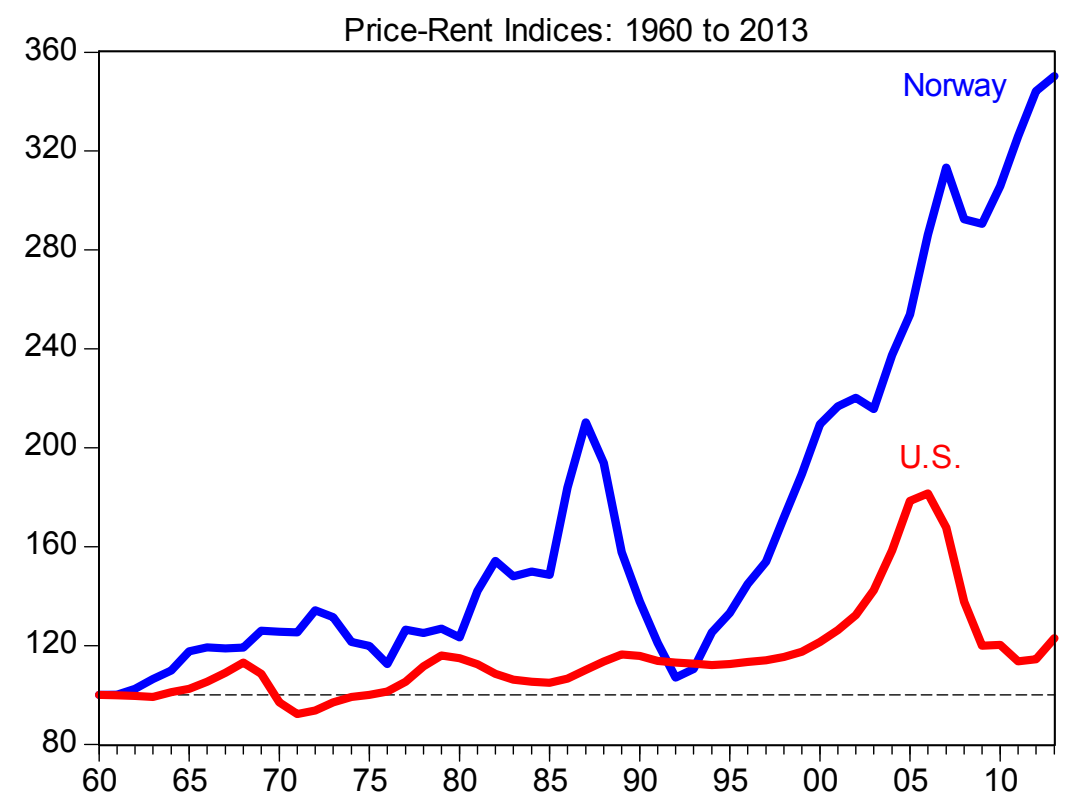

Figure 2: Price-rent indices for U.S. and Norway. The U.S. price-rent ratio peaked in early 2006 and has since fallen to its pre-boom level. The price-rent ratio for Norway has continued to trend upwards and currently stands more than 60 percent above the last major peak achieved two decades ago. Price-rent ratios are indexed to 100 in 1960.

most of the 20th century. Norway and other Nordic countries experienced a major house price boom in the late 1980s followed by a crash in the early 1990s . The earlier boom-bust pattern in Norway is similar in magnitude to the recent boom-bust pattern in U.S. house prices (Knutsen 2012). After peaking in 2006, U.S. real house prices have since dropped by nearly 40 percent. Starting in the late 1990s, Norwegian house prices experienced another major boom but so far no bust. On the contrary, real house prices in Norway have continued to rise by nearly 30 percent since 2006 .

Figure 2 plots price-rent ratios in the U.S. and Norway from 1960 onwards. The U.S. ratio peaked in early 2006 and has since returned to its pre-boom level. The price-rent ratio for Norway has continued to trend upwards and currently stands more than 60 percent above the last major peak achieved two decades ago. Although not plotted, price-income ratios for the two countries display a similar pattern. ${ }^{7}$

Figure 3 plots the results of a survey which asks Norwegian households about expected house price changes over the next year. The percentage of households who believe that property prices will keep rising went up from a low of 10 percent in 2008 to nearly 70 percent in 2012 .

\footnotetext{
${ }^{7}$ See Jurgilas and Lansing (2013).
} 


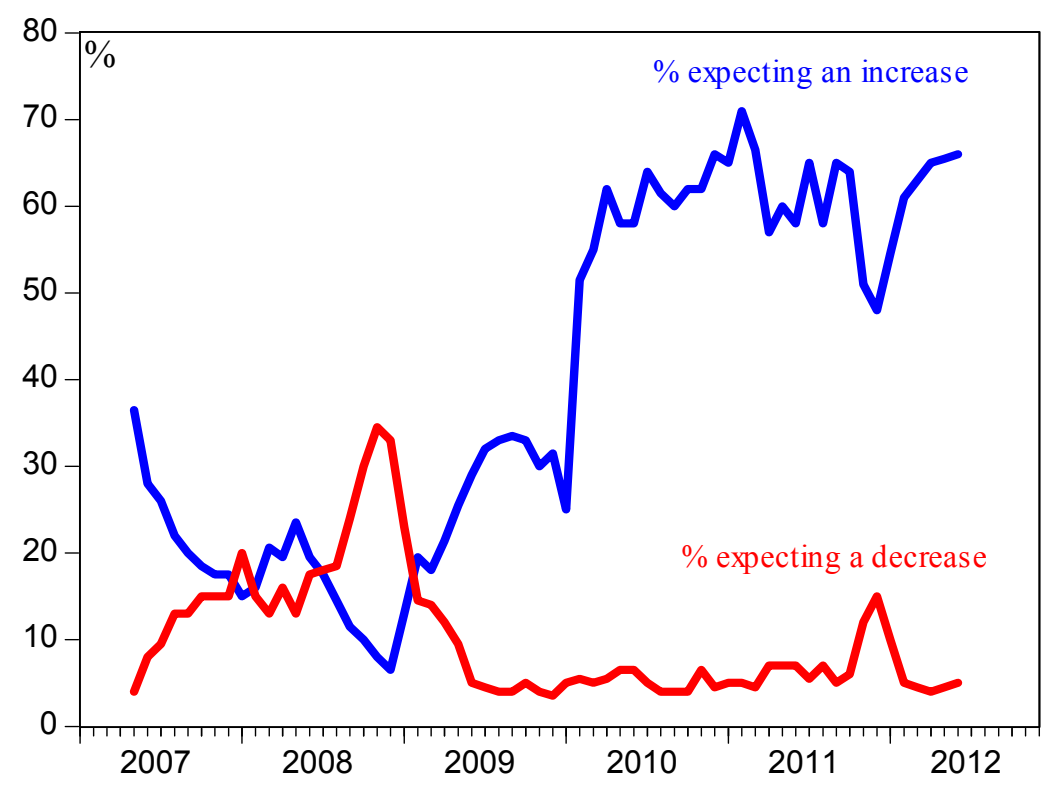

Figure 3: Norwegian survey data. The percentage of Norwegian households who believe that property prices will keep rising went up from a low of 10 percent in 2008 to nearly 70 percent in 2012. The data suggest that Norwegians expect high future returns on real estate even after a sustained run-up in the price-rent ratio. Data source: Financial Supervisory Authority of Norway.

Comparing Figure 3 to the price-rent ratio for Norway in Figure 2 suggests that Norwegians expect high future returns on real estate even after a sustained run-up in the price-rent ratio. This pattern is directly at odds with the idea of rationally low risk premiums driving the runup. Jurgilas and Lansing (2013) show that the balance of Norwegian households expecting a house price increase over the next year is strongly correlated with nominal house price growth over the preceding year, suggestive of a moving-average type forecast rule.

Figure 4 provides a more detailed look at U.S. house prices and rents using quarterly data from 1960.Q1 to 2013.Q3. ${ }^{8}$ The bottom two panels plot the quarterly net real return on housing together with the quarterly log real price change (in percent). ${ }^{9}$ Returns and log price changes were consistently positive and rising during the U.S. housing boom of the mid-2000s. After observing a long string of high housing returns, it seems quite natural that lenders and

\footnotetext{
${ }^{8}$ Quarterly data for U.S. nominal house prices and nominal rents are from www.lincolninst.edu, using the Case-Shiller-Weiss price data from the year 2000 onwards, as documented in Davis, Lehnert, and Martin (2008). Nominal values are converted to real values using the Consumer Price Index (all items) from the Federal Reserve Bank of St Louis.

${ }^{9}$ The first-order condition for housing services in our model (4) implies that the quarterly gross housing return in period $t+1$ is given by $p_{t+1} /\left(p_{t}-n_{t}\right)$, where $p_{t}$ is the "cum dividend" real house price and $n_{t}$ is the quarterly housing dividend (imputed real rent) which is received by the agent at time $t$.
} 

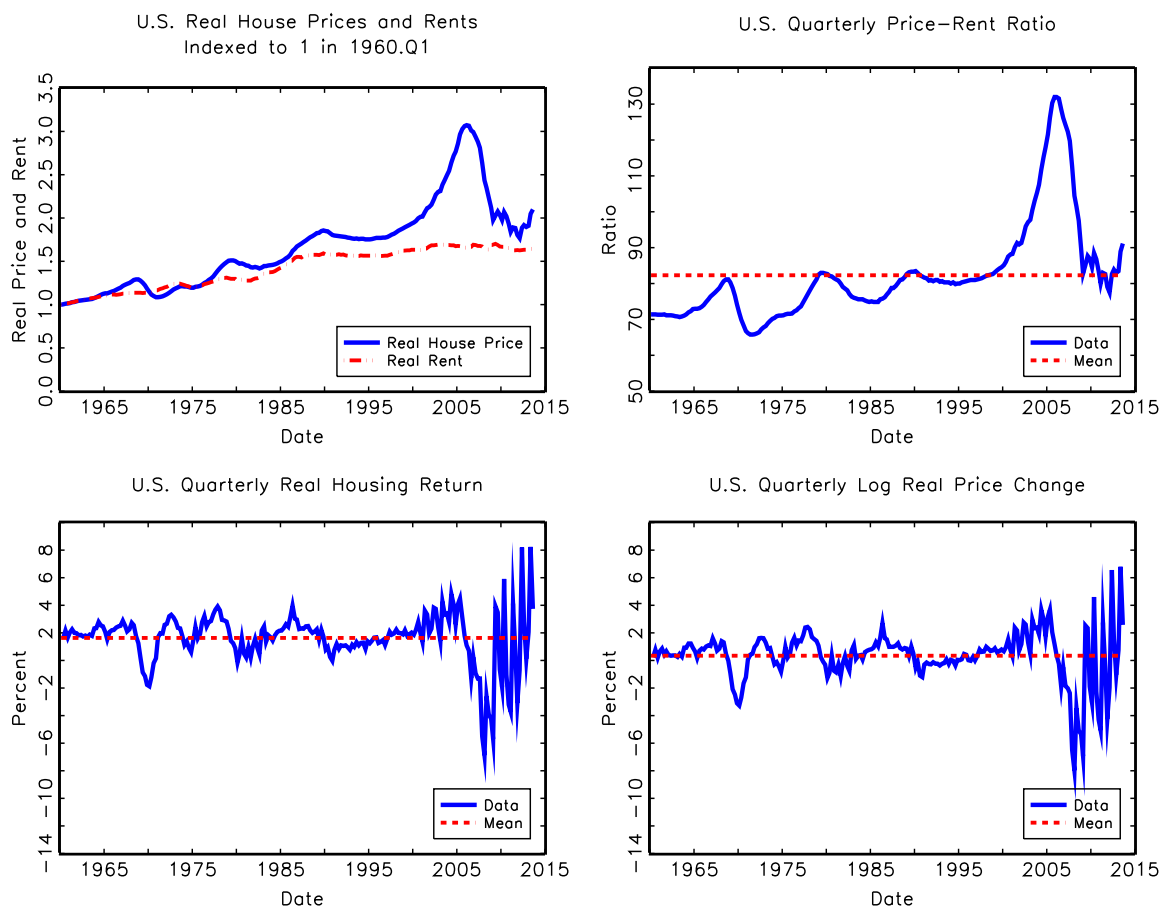

Figure 4: U.S. housing market data. Quarterly housing returns and log price changes were consistently positive and rising during the U.S. housing boom of the mid-2000s.

homebuyers would have expected the high returns to continue, as confirmed by the survey evidence.

Figure 5 plots quarterly rent growth in the data together with rolling summary statistics for window lengths of 4-years and 10-years. All of the summary statistics exhibit considerable variation. For example, the rolling 10-year autocorrelation coefficient (lower left panel) ranges from a low of -0.17 to a high of 0.75 . Variation of this magnitude can have significant implications for the quantitative predictions of rational asset pricing models, particularly in the presence of habit formation (Otrok, et al. 2002). To capture this feature of the data, we allow fundamental rent growth in the model to exhibit time varying persistence and volatility, as described in the next section.

\section{Model}

Housing services are priced using a version of the frictionless pure exchange model of Lucas (1978). The representative agent's problem is to choose sequences of $c_{t}$ and $h_{t}$ to maximize

$$
\widehat{E}_{0} \sum_{t=0}^{\infty} \beta^{t} \frac{\left(c_{t}^{\theta} h_{t}^{1-\theta}-\kappa C_{t-1}^{\theta} H_{t-1}^{1-\theta}\right)^{1-\alpha}-1}{1-\alpha},
$$


U.S. Quarterly Real Rent Growth

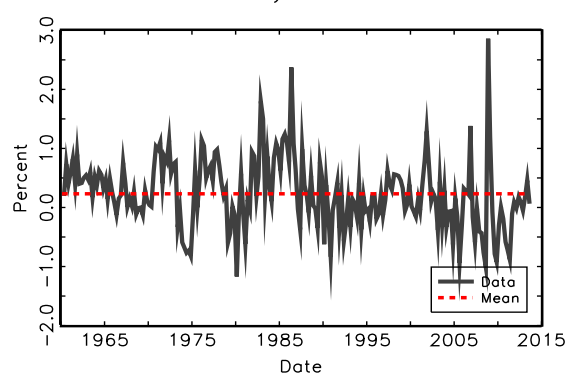

Rolling Persistence

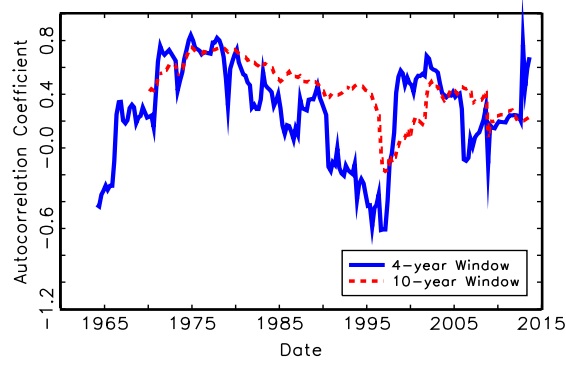

Rolling Mean

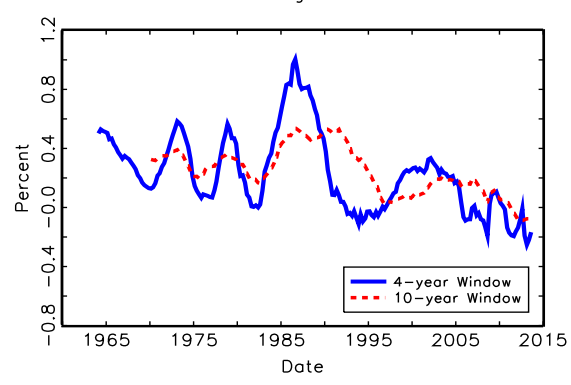

Rolling Volatility

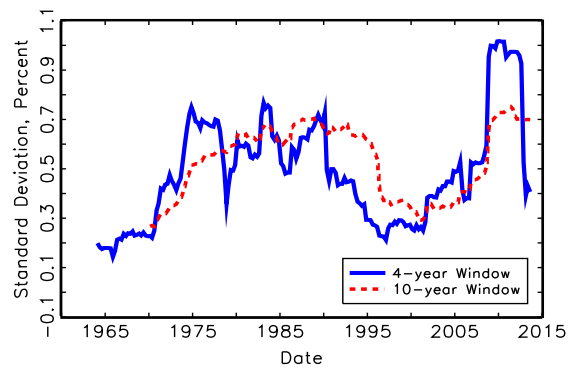

Figure 5: Properties of real rent growth in U.S. data. Real rent growth exhibits time-varying mean, persistence and volatility.

subject to the budget constraint

$$
c_{t}+p_{t}\left(h_{t}-h_{t-1}\right)=y_{t}, \quad c_{t}, h_{t} \geq 0
$$

where $c_{t}$ is the individual agent's consumption in period $t, h_{t}$ is the individual agent's housing service flow, $y_{t}$ is income, $\beta$ is the subjective time discount factor, and $\alpha$ is a curvature parameter that influences the coefficient of relative risk aversion. We use the capital letters $C_{t}$ and $H_{t}$ to denote the aggregate per capita quantities of consumption and housing which the agent views as outside of his control. After individual choices are made, we impose the aggregate equilibrium conditions $c_{t}=C_{t}$ and $h_{t}=H_{t}$ for all $t$. When $\alpha=1$, the within-period utility function can be written as $\log \left(c_{t}^{\theta} h_{t}^{1-\theta}-\kappa C_{t-1}^{\theta} H_{t-1}^{1-\theta}\right)$. To allow for time-varying risk aversion, we assume that an individual agent's felicity is measured relative to the lagged aggregate consumption basket. ${ }^{10}$ The parameter $\kappa \geq 0$ governs the importance of the external habit stock. The symbol $\widehat{E}_{t}$ represents the agent's subjective expectation, conditional on information available at time $t$, as explained more fully below. Under rational expectations, $\widehat{E}_{t}$ corresponds to the mathematical expectation operator $E_{t}$ evaluated using the objective distribution of shocks, which are assumed known by the rational household. The symbol $p_{t}$ is the price of housing services in consumption units.

\footnotetext{
${ }^{10}$ Maurer and Meier (2008) find strong empirical evidence for "peer-group effects" on individual consumption decisions using panel data on U.S. household expenditures. Otrok, et al. (2002) show that a one-lag habit specification similar to (1) can match the historical mean U.S. equity premium.
} 
We formulate the current-period Lagrangian $£_{t}$ as

$$
\max _{c_{t}, h_{t},} £_{t}=\frac{\left(c_{t}^{\theta} h_{t}^{1-\theta}-\kappa C_{t-1}^{\theta} H_{t-1}^{1-\theta}\right)^{1-\alpha}-1}{1-\alpha}+\lambda_{t}\left[y_{t}+p_{t}\left(h_{t-1}-h_{t}\right)-c_{t}\right],
$$

where $\lambda_{t}$ is the Lagrange multiplier on the budget constraint (2). The first-order condition that governs the agent's choice of housing services $h_{t}$ is given by

$$
p_{t}=\underbrace{\left(\frac{1-\theta}{\theta}\right) c_{t}}_{\equiv n_{t}}+\widehat{E}_{t} M_{t+1} p_{t+1}
$$

where we have divided both sides by the marginal utility of consumption $\lambda_{t}$ and imposed the equilibrium condition that housing exists in unit net supply such that $h_{t}=1$ for all $t$. The term $M_{t+1} \equiv \beta\left(\lambda_{t+1} / \lambda_{t}\right)$ is the stochastic discount factor and $n_{t} \equiv c_{t}(1-\theta) / \theta$ is the imputed rent (or utility dividend) from housing, which is received by the agent in period $t$. Consequently, $p_{t}$ represents a "cum dividend" asset price.

Substituting $h_{t}=h_{t-1}$ into the budget constraint (2) yields, $c_{t}=y_{t}$ for all $t .{ }^{11}$ In equilibrium, the exponential growth rates of rent $\left(n_{t}\right)$, consumption $\left(c_{t}\right)$, and income $\left(y_{t}\right)$ are identical. In the data, imputed rent reflects not only the utility dividend, but also the marginal collateral value of the house in the case when the agent's borrowing constraint is binding. We illustrate this point analytically in Appendix A. Although we abstract from directly modeling a borrowing constraint, we can implicitly take the effects of leverage into account by calibrating the effective cash flows in the model to match the stochastic properties of U.S. rent growth. ${ }^{12}$

Rent growth in the model is governed by the following nonlinear law of motion

$$
x_{t+1} \equiv \log \left(\frac{n_{t+1}}{n_{t}}\right)=\bar{x}+\left(\rho+\psi \varepsilon_{t}\right)\left(x_{t}-\bar{x}\right)+\varepsilon_{t+1}, \quad \varepsilon_{t} \sim N\left(0, \sigma_{\varepsilon}^{2}\right),
$$

where $\bar{x}$ is the steady state growth rate which differs from the ergodic mean $E\left(x_{t}\right)=\bar{x}+$ $\psi \sigma_{\varepsilon}^{2} /(1-\rho)$ whenever $\psi \neq 0$. Equation (5) is a simple version of the bilinear time series model originally developed by Granger and Andersen (1978) and explored further by Sesay and Subba Rao (1988). By appropriate choice of the parameters $\bar{x}, \rho, \sigma_{\varepsilon}$, and $\psi$, the above specification can match the unconditional moments of U.S. rent growth and deliver timevarying persistence and volatility, consistent with the data.

The equilibrium stochastic discount factor (after imposing $h_{t}=1$ ) is

$$
\begin{aligned}
M_{t+1} & =\beta\left(\frac{c_{t+1}}{c_{t}}\right)^{-\theta \alpha-1+\theta}\left[\frac{1-\kappa\left(c_{t+1} / c_{t}\right)^{-\theta}}{1-\kappa\left(c_{t} / c_{t-1}\right)^{-\theta}}\right]^{-\alpha}, \\
& =\beta \exp \left[(-\theta \alpha-1+\theta) x_{t+1}\right]\left[\frac{1-\kappa \exp \left(-\theta x_{t+1}\right)}{1-\kappa \exp \left(-\theta x_{t}\right)}\right]^{-\alpha},
\end{aligned}
$$

\footnotetext{
${ }^{11}$ Following Otrok, et al. (2002) we impose an upper bound on the ratio $C_{t-1} / c_{t}$ to ensure that the utility function (1) is always well defined. The upper bound is never reached in the model simulations.

${ }^{12}$ Ayuso and Restoy (2006) and Piazzesi, et al. (2007) similarly abstract from modeling a borrowing constraint in the context of equilibrium asset pricing models applied to housing.
} 
where we have made use of the fact that model consumption growth and model rent growth are identical. ${ }^{13}$

Dividing both sides of the first-order condition (4) by the current period rent $n_{t}$ and substituting in the expression for $M_{t+1}$ yields

$$
\frac{p_{t}}{n_{t}}=1+\beta \widehat{E}_{t} \exp \left\{[\theta(1-\alpha)] x_{t+1}\right\}\left[\frac{1-\kappa \exp \left(-\theta x_{t+1}\right)}{1-\kappa \exp \left(-\theta x_{t}\right)}\right]^{-\alpha} \frac{p_{t+1}}{n_{t+1}},
$$

which shows that the price-rent ratio in period $t$ depends on the agent's subjective joint forecast of next period's rent growth $x_{t+1}$ and next period's price-rent ratio $p_{t+1} / n_{t+1}$. It is convenient to transform equation (7) using a nonlinear change of variables to obtain

$$
\begin{aligned}
z_{t} & =g\left(x_{t}\right)+\beta \exp \left\{[\theta(1-\alpha)] x_{t}\right\} \widehat{E}_{t} z_{t+1} \\
\text { where } z_{t} & \equiv g\left(x_{t}\right) \frac{p_{t}}{n_{t}} \\
g\left(x_{t}\right) & \equiv \frac{\exp \left\{[\theta(1-\alpha)] x_{t}\right\}}{\left[1-\kappa \exp \left(-\theta x_{t}\right)\right]^{\alpha}}
\end{aligned}
$$

Under this formulation, $z_{t}$ represents the composite variable that the agent must forecast. In the special case when $\alpha=1$ and $\kappa=0$ (log utility, no habit formation), we have $g\left(x_{t}\right)=1$ such that $z_{t}=p_{t} / n_{t}$. The transformed first-order condition (8) shows that the value of the composite variable $z_{t}$ in period $t$ depends on the agent's subjective forecast of that same variable.

By making use of the definition of $z_{t}$, equation (7) can be written as

$$
\frac{p_{t}}{n_{t}}=1+\beta\left[1-\kappa \exp \left(-\theta x_{t}\right)\right]^{\alpha} \widehat{E}_{t} z_{t+1},
$$

which shows that the agent's subject forecast $\widehat{E}_{t} z_{t+1}$ has a direct influence on the dynamics of the equilibrium price-rent ratio $p_{t} / n_{t}$.

Equation (4) can be rearranged to obtain the standard relationship

$$
1=\widehat{E}_{t}\left[M_{t+1} R_{t+1}\right], \quad R_{t+1} \equiv \frac{p_{t+1}}{p_{t}-n_{t}},
$$

where $R_{t+1}$ is the gross return on housing from period $t$ to $t+1$.

\subsection{Rational Expectations}

Our solution for the composite variable $z_{t}$ employs an analytical perturbation method. The point of approximation for the solution is the ergodic mean, not the deterministic steady state, which helps to improve accuracy. ${ }^{14}$

\footnotetext{
${ }^{13}$ Over the period 1960 to 2013, the correlation coefficient in U.S. data between quarterly real rent growth and quarterly real per capita consumption growth (nondurables and services) is 0.47 .

${ }^{14}$ Lansing (2010) demonstrates the accuracy of this solution method for the case of AR(1) dividend growth. Use of the ergodic mean as the approximation point eliminates a significant source of error in the constant term of the approximate solution, as shown by Collard and Juillard (2001).
} 
Proposition 1. An approximate analytical solution for the value of the composite variable $z_{t} \equiv g\left(x_{t}\right) p_{t} / n_{t}$ under rational expectations is given by

$$
z_{t}=a_{0} \exp \left\{a_{1}\left[x_{t}-E\left(x_{t}\right)\right]+a_{2}\left(v_{t}-\sigma_{\varepsilon}^{2}\right)\right\},
$$

where $v_{t} \equiv \varepsilon_{t}\left(x_{t}-\bar{x}\right)$ such that $E\left(v_{t}\right)=\sigma_{\varepsilon}^{2}$. The constants $a_{0} \equiv \exp \left\{E\left[\log \left(z_{t}\right)\right]\right\}$, $a_{1}$, and $a_{2}$ are Taylor series coefficients that depend on the preference parameters $\beta, \theta, \alpha, \kappa$, and the rent growth parameters $\bar{x}, \rho, \sigma_{\varepsilon}$, and $\psi$.

Proof: See Appendix B.

The approximate solution in Proposition 1 preserves the nonlinear features of the model in several ways. First, rent growth $x_{t}$ is a state variable that follows a nonlinear law of motion, as given by equation (5). Second, the solution for $z_{t}$ depends on the state variable $v_{t} \equiv \varepsilon_{t}\left(x_{t}-\bar{x}\right)$ which also follows a nonlinear law of motion, as derived in Appendix B. Third, given the solution for $z_{t}$, the price-rent ratio is determined as a nonlinear function of the state variable $x_{t}$, such that $p_{t} / n_{t}=z_{t} / g\left(x_{t}\right)$. In the model simulations, we use the approximate solution in Proposition 1 to construct the conditional forecast $E_{t} z_{t+1}$ each period using the expression derived in Appendix A. We then substitute the resulting forecast value into the nonlinear first-order condition (8) to obtained the realized value of the composite variable $z_{t}$ each period.

To compute the expected return on housing, we rewrite the gross housing return as

$$
\begin{aligned}
R_{t+1} & =\left[\frac{p_{t+1} / n_{t+1}}{p_{t} / n_{t}-1}\right] \exp \left(x_{t+1}\right), \\
& =\left[\frac{\left[1-\kappa \exp \left(-\theta x_{t+1}\right)\right]^{\alpha} \exp \left\{[-\theta(1-\alpha)] x_{t+1}\right\} z_{t+1}}{\beta\left[1-\kappa \exp \left(-\theta x_{t}\right)\right]^{\alpha} E_{t} z_{t+1}}\right] \exp \left(x_{t+1}\right), \\
& =\left[\frac{1-\kappa \exp \left(-\theta x_{t+1}\right)}{1-\kappa \exp \left(-\theta x_{t}\right)}\right]^{\alpha} \exp \left\{[1-\theta(1-\alpha)] x_{t+1}\right\} \frac{z_{t+1}}{\beta E_{t} z_{t+1}},
\end{aligned}
$$

where we have eliminated $p_{t+1} / n_{t+1}$ using the definitional relationships for $z_{t+1}$ and $g\left(x_{t+1}\right)$, and we have eliminated $p_{t} / n_{t}$ using the transformed first-order condition (9). ${ }^{15}$

From equation (11), the conditional expectation of the log return is given by

$$
\begin{aligned}
E_{t} \log \left(R_{t+1}\right)= & -\log (\beta)-\alpha \log \left[1-\kappa \exp \left(-\theta x_{t}\right)\right]+E_{t} \log \left(z_{t+1}\right)-\log \left(E_{t} z_{t+1}\right) \\
& +\alpha E_{t} \log \left[1-\kappa \exp \left(-\theta x_{t+1}\right)\right]+[1-\theta(1-\alpha)] E_{t} x_{t+1},
\end{aligned}
$$

where the conditional forecasts for terms involving $x_{t+1}$ are computed using the true law of motion for rent growth (5) and the conditional forecasts $E_{t} z_{t+1}$ and $E_{t} \log z_{t+1}$ are computed using the approximate rational solution from Proposition 1 , as detailed in the appendix. To derive an analytical expression for $E_{t} \log \left(R_{t+1}\right)$, we approximate the nonlinear term

\footnotetext{
${ }^{15}$ Our procedure for expressing the rational return on the risky asset in terms of the composite forecast variable $z_{t}$ follows Lansing and LeRoy (2014).
} 
$\log \left[1-\kappa \exp \left(-\theta x_{t+1}\right)\right]$ in (12) using the expression $d_{0}+d_{1}\left[x_{t+1}-E\left(x_{t}\right)\right]$, where $d_{0}$ and $d_{1}$ are Taylor series coefficients.

The conditional expectation of the 4-quarter compound return is formulated as

$$
E_{t} \underbrace{\left[r_{t+1 \rightarrow t+4}\right]}_{\text {4-quarter return }}=E_{t} \sum_{j=1}^{4} \log \left(R_{t+j}\right),
$$

where the terms $E_{t} \log \left(R_{t+i}\right)$ for $i=2,3,4$ are computed by iterating equation (11) forward, taking logs, linearizing where necessary, and then applying the law of iterated expectations.

\subsection{Near-Rational Expectations}

The rational expectations solution in Proposition 1 is based on strong assumptions about the representative agent's information set. Specifically, the fully-rational solution assumes that agents know the true stochastic process for rent growth (5) which exhibits time-varying persistence and volatility. An agent with less information may be inclined to view rent growth as being governed by an AR(1) process with shifting parameters - a specification that could also account for the appearance of time-varying moments in the observed rent growth data. Along these lines, we consider a near-rational agent who has the following perceived law of motion (PLM) for rent growth.

$$
x_{t+1}=\bar{x}_{t}+\gamma_{t}\left(x_{t}-\bar{x}_{t}\right)+\eta_{t+1}, \quad \eta_{t} \sim N\left(0, \sigma_{\eta, t}^{2}\right),
$$

where $\bar{x}_{t}, \gamma_{t}$, and $\sigma_{\eta, t}$ are the perceived time-varying $\operatorname{AR}(1)$ parameters.

Following the learning literature, we assume that agents estimate the parameters of the PLM (14) using recent data. In this way, agents seek to account for perceived shifts in the parameters governing rent growth. Specifically, we assume that the near-rational agent infers the parameters of (14) by computing moments over a rolling sample window of length $T_{w}$ :

$$
\begin{aligned}
& \bar{x}_{t}=\operatorname{Mean}\left(\left\{x_{j}\right\}\right), \quad \text { where } j \in\left[t-T_{w}+1, t\right], \\
& \gamma_{t}=\operatorname{Corr}\left(\left\{x_{j}\right\},\left\{x_{j-1}\right\}\right), \\
& \sigma_{\eta, t}=\sqrt{\operatorname{Var}\left(\left\{x_{j}\right\}\right)\left(1-\gamma_{t}^{2}\right)},
\end{aligned}
$$

where $\left\{x_{j}\right\}$ represents the sample of rent growth observations in the most-recent moving window. The learning mechanism summarized by equations (15) through (17) is a version of the sample autocorrelation learning (SAC) algorithm described by Hommes and Sorger (1998). The advantage of this algorithm is that it endogenously enforces the restriction $\gamma_{t} \in(-1,1)$, which ensures that perceived rent growth is always stationary. ${ }^{16}$

\footnotetext{
${ }^{16}$ For other applications of the SAC learning algorithm, see Lansing (2009, 2010) and Hommes and Zhu (2014).
} 
If the true law of motion for rent growth was governed by an $\mathrm{AR}(1)$ process with constant parameters, then the rational expectations solution would take the form shown in Proposition 1 , but with $a_{2}=0$. Under "near-rational" expectations, we assume that the representative agent employs the correct perceived form of the rational solution, but the agent continually updates the parameters of the perceived rent growth process (14), which in turn delivers shifting coefficients in the perceived optimal forecast rule.

As shown in Appendix C, the near-rational agent's conjectured solution for the composite variable $z_{t}$ takes the form

$$
\begin{aligned}
z_{t} & \simeq b_{0, t} \exp \left[b_{1, t}\left(x_{t}-\bar{x}_{t}\right)\right], \quad(\mathrm{PLM}) \\
\widehat{E}_{t} z_{t+1} & =b_{0, t} \exp \left[b_{1, t} \gamma_{t}\left(x_{t}-\bar{x}_{t}\right)+\frac{1}{2}\left(b_{1, t}\right)^{2} \sigma_{\eta, t}^{2}\right],
\end{aligned}
$$

where $b_{0, t}$ and $b_{1, t}$ depend on the most recent estimates of the $\operatorname{AR}(1)$ parameters $\bar{x}_{t}, \gamma_{t}$, and $\sigma_{\eta, t}$. We follow the common practice in the learning literature by assuming that the representative agent views the most recent parameter estimates as permanent when computing the subjective forecast $\widehat{E}_{t} z_{t+1} \cdot{ }^{17}$

Substituting the subjective forecast (19) into the nonlinear first-order condition (8), yields the following actual law of motion (ALM) for the composite variable $z_{t}$ :

$$
z_{t}=g\left(x_{t}\right)+\beta b_{0, t} \exp \left\{[\theta(1-\alpha)] x_{t}+b_{1, t} \gamma_{t}\left(x_{t}-\bar{x}_{t}\right)+\frac{1}{2}\left(b_{1, t}\right)^{2} \sigma_{\eta, t}^{2}\right\} .
$$

Following the methodology described earlier for rational expectations, the near-rational conditional expectation of the log return is given by

$$
\begin{aligned}
\widehat{E}_{t} \log \left(R_{t+1}\right)= & -\log (\beta)-\alpha \log \left[1-\kappa \exp \left(-\theta x_{t}\right)\right]+\widehat{E}_{t} \log \left(z_{t+1}\right)-\log \left(\widehat{E}_{t} z_{t+1}\right) \\
& +\alpha \widehat{E}_{t} \log \left[1-\kappa \exp \left(-\theta x_{t+1}\right)\right]+[1-\theta(1-\alpha)] \widehat{E}_{t} x_{t+1},
\end{aligned}
$$

where the subjective forecasts involving $x_{t+1}$ are now computed using the agent's perceived law of motion (14) and the subjective forecasts $\widehat{E}_{t} z_{t+1}$ and $\widehat{E}_{t} \log z_{t+1}$ are computed using the agent's conjectured solution (18), as shown in Appendix C. To derive an analytical expression for $\widehat{E}_{t} \log \left(R_{t+1}\right)$, we approximate the nonlinear term $\log \left[1-\kappa \exp \left(-\theta x_{t+1}\right)\right]$ in $(21)$ using the expression $d_{0, t}+d_{1, t}\left(x_{t+1}-\bar{x}_{t}\right)$, where $d_{0, t}$ and $d_{1, t}$ are time-varying Taylor series coefficients that shift over time due to the agent's perception that the approximation point $\bar{x}_{t}$ is shifting.

The near-rational agent's forecast for the 4-quarter compound return is formulated along the lines of equation (13), but now the subjective expectation operator $\widehat{E}_{t}$ is used in place of the mathematical expectation operator $E_{t}$ and the agent's perceived laws of motion are used in place of the actual laws of motion when computing the subjective forecasts.

\footnotetext{
${ }^{17}$ Otrok, et al. (2002) employ a similar procedure which they describe (p. 1275) as "a kind of myopic learning." For an earlier example of this type of learning applied to the U.S. stock market, see Barsky and Delong (1993). More recently, Collin-Dufresne, et al. (2012) examine the asset pricing implications of fullyrational learning about the parameters of dividend growth. In their model, the agent's rational forecast takes into account the expected future shifts in the estimated parameters via Bayes law.
} 


\subsection{Moving-Average Expectations}

Motivated by the survey evidence described in Section 2, we consider a forecast rule that is based on an exponentially-weighted moving-average of past observed values of the relevant forecast variable. Such a forecast requires only a minimal amount of computational and informational resources. Specifically, the agent does not need to know or estimate the underlying stochastic process for rent growth. ${ }^{18}$ The agent's subjective forecast rule is given by:

$$
\begin{aligned}
\widehat{E}_{t} z_{t+1} & =\lambda z_{t}+(1-\lambda) \widehat{E}_{t-1} z_{t}, \quad \lambda \in[0,1], \\
& =\lambda\left[z_{t}+(1-\lambda) z_{t-1}+(1-\lambda)^{2} z_{t-2}+\ldots\right],
\end{aligned}
$$

where we formulate the moving average in terms of the composite variable $z_{t}$ that appears in the transformed first-order condition (8). In simulations of the moving average model, the composite variable $z_{t}$ exhibits a correlation coefficient of 0.98 with the price-rent ratio $p_{t} / n_{t}$. Hence, we can roughly think of the agent as applying a moving average forecast rule to the price-rent ratio itself.

Substituting $\widehat{E}_{t} z_{t+1}$ from equation (22) into the transformed first-order condition (8) yields the following actual law of motion for the composite variable $z_{t}$ :

$$
z_{t}=\frac{g\left(x_{t}\right)}{1-\beta \lambda \exp \left\{[\theta(1-\alpha)] x_{t}\right\}}+\frac{\beta(1-\lambda) \exp \left\{[\theta(1-\alpha)] x_{t}\right\}}{1-\beta \lambda \exp \left\{[\theta(1-\alpha)] x_{t}\right\}} \widehat{E}_{t-1} z_{t},
$$

where the previous subjective forecast $\widehat{E}_{t-1} z_{t}$ is an endogenous state variable that evolves according to the following law of motion:

$$
\widehat{E}_{t} z_{t+1}=\frac{\lambda g\left(x_{t}\right)}{1-\beta \lambda \exp \left\{[\theta(1-\alpha)] x_{t}\right\}}+\left[\frac{1-\lambda}{1-\beta \lambda \exp \left\{[\theta(1-\alpha)] x_{t}\right\}}\right] \widehat{E}_{t-1} z_{t} .
$$

We postulate that the agent's subjective forecast for the 4-quarter compound return is constructed in the same way as the forecast for $z_{t+1}$. Specifically, the subjective return forecast is constructed as a moving-average of past observed 4-quarter returns, where the same weight $\lambda$ is applied to the most recent return observation.

$$
\widehat{E}_{t} \underbrace{\left[r_{t+1 \rightarrow t+4}\right]}_{4-\text { quarter return }}=\lambda\left[r_{t-4 \rightarrow t}\right]+(1-\lambda) \widehat{E}_{t-1}\left[r_{t-4 \rightarrow t}\right]
$$

\section{Calibration}

Table 1 shows the baseline parameter values used in the model simulations. We also examine the sensitivity of the results to a range of values for some key parameters, namely the utility function parameters $\alpha$ and $\kappa$, and the forecast rule parameters $T_{w}$ and $\lambda$.

\footnotetext{
${ }^{18}$ As noted by Nerlove (1983, p. 1255): "Purposeful economic agents have incentives to eliminate errors up to a point justified by the costs of obtaining the information necessary to do so...The most readily available and least costly information about the future value of a variable is its past value."
} 
Table 1. Baseline Parameter Values

\begin{tabular}{ccl}
\hline \hline Parameter & Value & \multicolumn{1}{c}{ Description/Target } \\
\hline$\alpha$ & 2 & Utility function curvature parameter. \\
$\kappa$ & 0.8 & Utility function habit parameter. \\
$\beta$ & 0.99 & Match mean of U.S. price/quarterly rent ratio $=82.3$. \\
$\theta$ & 0.87 & Match mean of U.S. price/quarterly income ratio $=12$. \\
$\bar{x}$ & $0.0122 \%$ & Match mean of U.S. quarterly real rent growth. \\
$\rho$ & 0.392 & Match autocorrelation of U.S. rent growth. \\
$\sigma_{\varepsilon}$ & $0.450 \%$ & Match std. dev. of U.S. quarterly real rent growth. \\
$\psi$ & 66.2 & Match skewness of U.S. quarterly real rent growth. \\
$T_{w}$ & 16 quarters & Match std. dev. of U.S. price/quarterly rent $=13.65$. \\
$\lambda$ & 0.94 & Match std. dev. of U.S. price/quarterly rent $=13.65$. \\
\hline
\end{tabular}

The utility function (1) implies the following expression for the coefficient of relative risk aversion $\left(\mathrm{CRRA}_{t}\right)$ :

$$
\mathrm{CRRA}_{t}=-\frac{c_{t} U_{c c}}{U_{c}}=\frac{\alpha \theta}{1-\kappa \exp \left(-\theta x_{t}\right)}+1-\theta
$$

which yields $\mathrm{CRRA}_{t}=8.8$ for the baseline calibration when $x_{t}=E\left(x_{t}\right)$. During the simulations of the baseline model, the risk aversion coefficient ranges from a low of 7.7 to a high of 9.4. Hence, our baseline calibration keeps the risk aversion coefficient below the maximum level of 10 considered plausible by Mehra and Prescott (1985). ${ }^{19}$ Later in Figure 8, we consider values for $\alpha$ and $\kappa$ that allow for much higher values of the risk aversion coefficient.

The parameters $\beta$ and $\theta$ are chosen simultaneously so that the rational expectations model exhibits a mean price-rent ratio and a mean price-income ratio which are close to the sample means in U.S. data. ${ }^{20}$ Quarterly data on U.S. price-rent ratios from 1960 to 2013 are from the Lincoln Land Institute (see footnote 8). Data on U.S. price-income ratios for the period 1985 to 2012 are from Gudell (2012). The same values of $\beta$ and $\theta$ are used for the near-rational model and the moving-average model.

We choose the rent growth parameters $\bar{x}, \rho, \sigma_{\varepsilon}$, and $\psi$ to match the mean, first-order autocorrelation, standard deviation, and skewness of real rent growth in U.S. data over the period 1960.Q2 to 2013.Q3. The analytical moment formulas for model rent growth are contained in Appendix D. The calibrated value of $\bar{x}$ turns out to be considerably smaller than the mean growth rate in the data because the analytical moments imply $E\left(x_{t}\right)=\bar{x}+\psi \sigma_{\varepsilon}^{2} /(1-\rho)$. Table 2 compares the properties of U.S. rent growth to those produced by a long simulation of the model. In addition to hitting the four target moments, the model does a reasonably good job of replicating the second-order autocorrelation of U.S. rent growth, the kurtosis of rent growth, and some moments of rent growth changes, i.e., $\Delta x_{t} \equiv x_{t}-x_{t-1}$.

\footnotetext{
${ }^{19}$ In the habit formation model of Campbell and Cochrane (1999), the calibration implies an extremely high coefficient of relative risk aversion-around 80 in the model steady state.

${ }^{20}$ Since $n_{t} / c_{t}=(1-\theta) / \theta$ and $y_{t} / c_{t}=1$, we have $p_{t} / y_{t}=(1 / \theta-1) p_{t} / n_{t}$, which is used to pin down the value of $\theta$. The value of $\beta$ is pinned down using the analytical expression for the Taylor series coefficient $a_{0}$ in Proposition 1.
} 

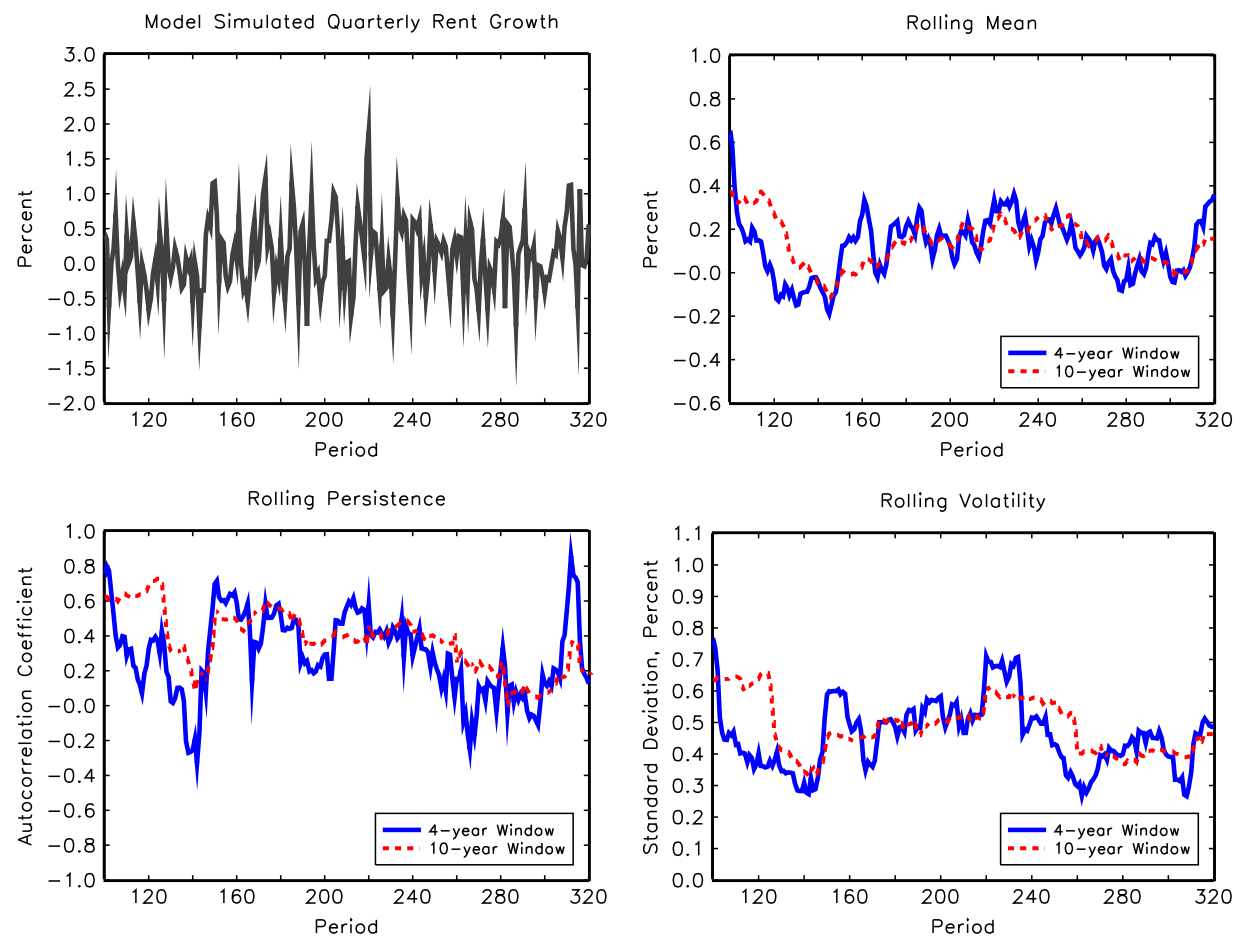

Figure 6: Properties of model rent growth. Model rent growth exhibits time-varying mean, persistence and volatility, similar to that exhibited by the U.S. data plotted in Figure 5. In the model, the near-rational agent's perception that the $\mathrm{AR}(1)$ parameters for real rent growth are shifting appears to be justified.

Table 2. Properties of Quarterly Real Rent Growth: Data versus Model

\begin{tabular}{lcc}
\hline \hline \multicolumn{1}{c}{ Statistic } & U.S. Data & \\
\hline Mean $\left(x_{t}\right)$ & $0.232 \%$ & Model \\
Std Dev $\left(x_{t}\right)$ & $0.571 \%$ & $0.226 \%$ \\
Corr $\left(x_{t}, x_{t-1}\right)$ & 0.48 & $0.569 \%$ \\
Corr $\left(x_{t}, x_{t-2}\right)$ & 0.27 & 0.49 \\
Skew $\left(x_{t}\right)$ & 0.62 & 0.18 \\
Kurt $\left(x_{t}\right)$ & 5.1 & 0.62 \\
Std Dev $\left(\Delta x_{t}\right)$ & $0.583 \%$ & 4.4 \\
Corr $\left(\Delta x_{t}, \Delta x_{t-1}\right)$ & -0.29 & $0.577 \%$ \\
\hline
\end{tabular}

Note: Model statistics are computed from a 15,000 period simulation.

\section{Quantitative Results}

Figure 6 plots simulated rent growth from the model together with 4-year and 10-year rolling summary statistics. The model statistics exhibit considerable variation over time, similar to 


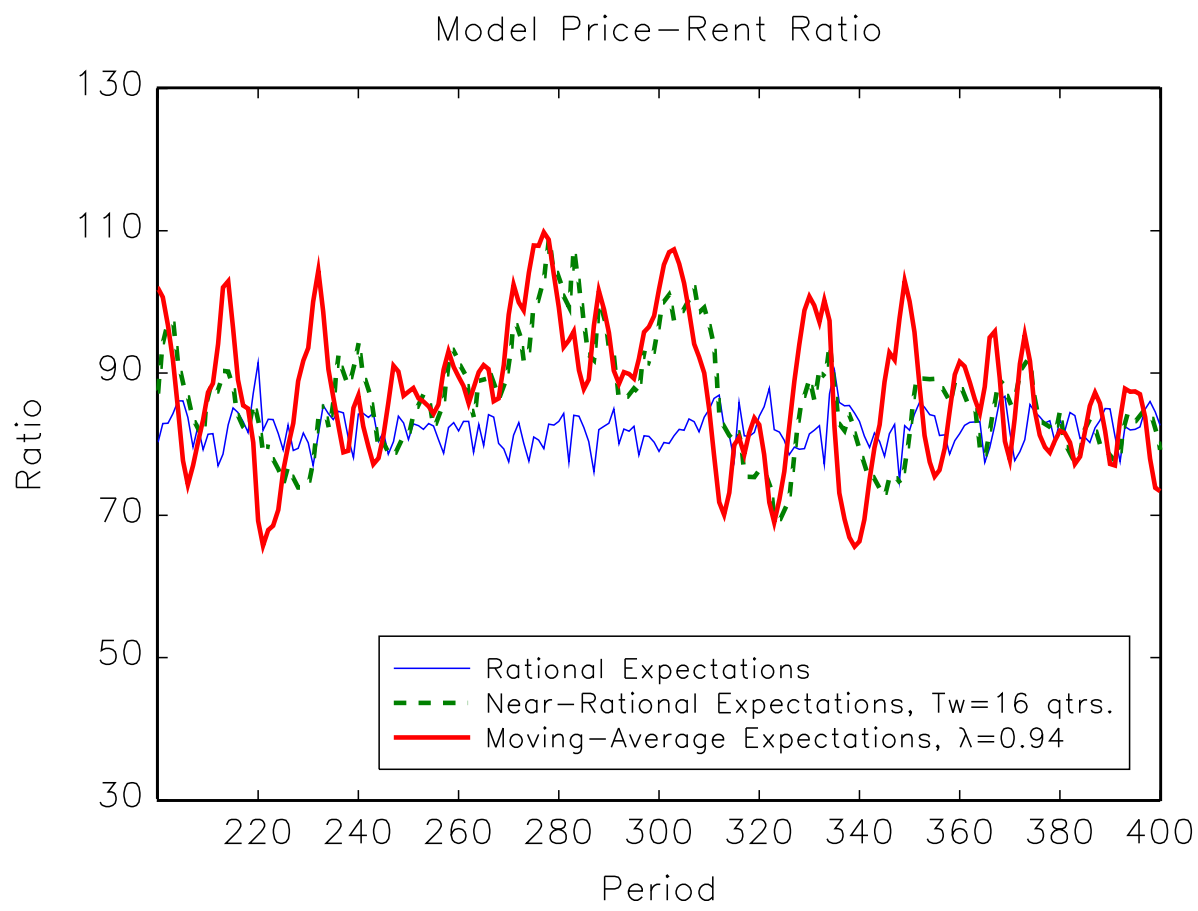

Figure 7: Price-rent ratios from model simulations. The standard deviation of the model price-rent ratio under rational expectations is 2.86 versus 13.65 in the data. Under the other two expectation regimes, the standard deviation of the model price-rent ratio is very close to that in the data.

the U.S. data statistics plotted earlier in Figure 5. An agent observing such variation would be inclined to believe that the parameters governing the stochastic process for rent growth are indeed changing over time, consistent with the near-rational PLM (14).

Figure 7 plots simulated price-rent ratios for the three different expectation regimes. The standard deviation of the model price-rent ratio under rational expectations is 2.86 versus 13.65 in the data. For the other two expectation regimes, the standard deviation of the simulated price-rent ratio is very close to that in the data. This is a direct consequence of our calibration of the forecast rule parameters $T_{w}$ and $\lambda$. Due to the self-referential nature of the transformed first-order condition (8), the form of the agent's subjective forecast $\widehat{E}_{t} z_{t+1}$ influences the dynamics of the object that is being forecasted. Interestingly, the near-rational and the moving-average forecast regimes produce similar patterns for the simulated price-rent ratio. The contemporaneous correlation between the simulated price-rent ratios in the two regimes is 0.80 . As we shall see, however, these two models have different implications for the correlation between the agent's expected future return on housing and the price-rent ratio. Only the moving-average model predicts a positive correlation between these two variables, consistent with the survey evidence summarized in section 2 . 

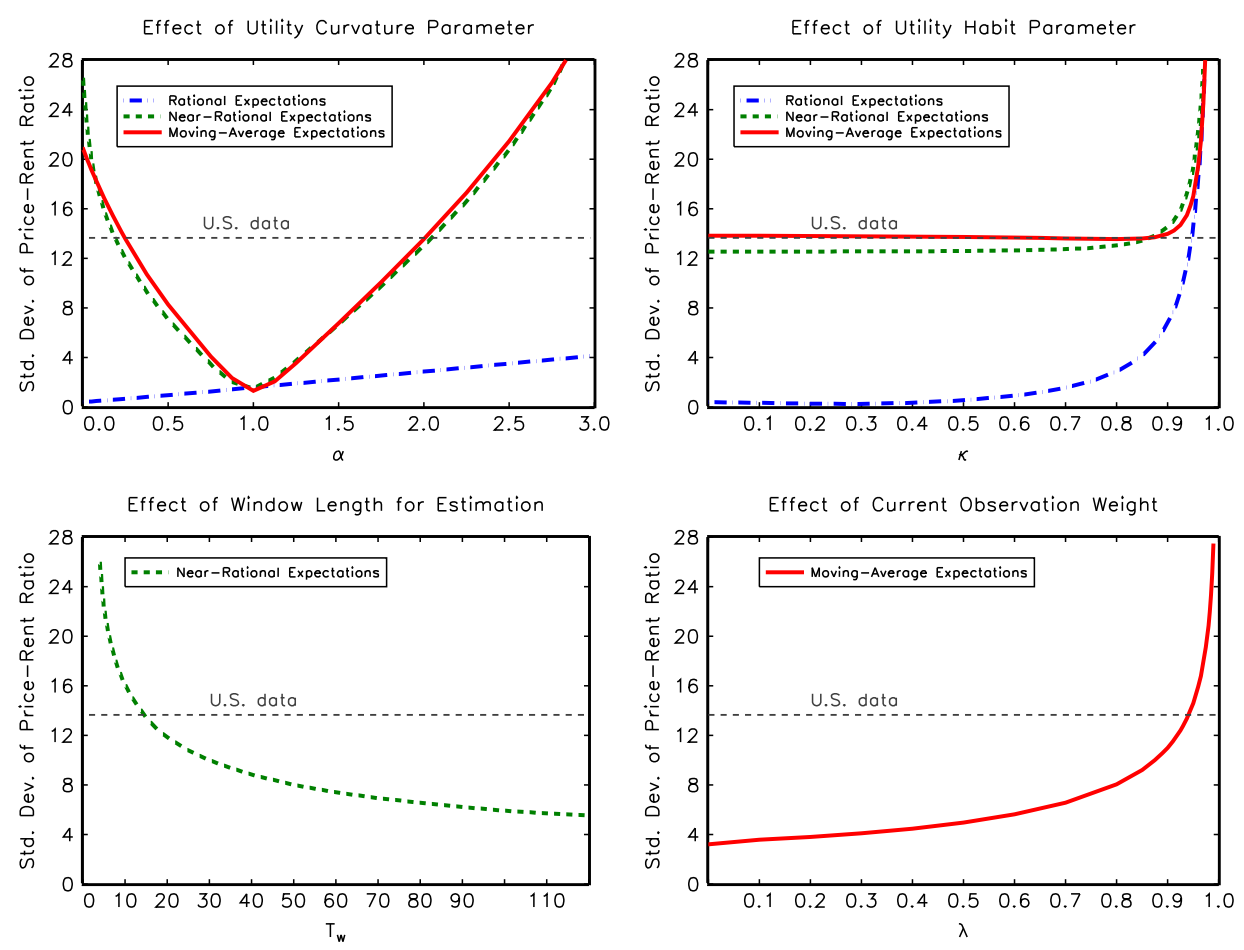

Figure 8: Sensitivity analysis. Using long-run simulations, the figure plots how different parameter values affect the volatility of the model price-rent ratio under each of the three expectation regimes. The rational expectations model can match the observed volatility in the data (dashed horizontal line) when $\kappa \simeq 0.945$ which implies a mean coefficient of relative risk aversion $\simeq 30$.

Table 3. Comparison of Percentage Forecast Errors

\begin{tabular}{llcl}
\hline \hline \multirow{2}{*}{ Statistic } & \multicolumn{3}{c}{ Model Simulations } \\
Mean $\left(\operatorname{err}_{t+1}\right)$ & 0.00 & 0.00 & MAE \\
$\sqrt{\operatorname{Mean}\left(\operatorname{err}_{t+1}^{2}\right)}$ & 0.009 & 0.045 & 0.00 \\
$\operatorname{Corr}\left(\operatorname{err}_{t+1}, \operatorname{err}_{t}\right)$ & 0.01 & 0.39 & 0.074 \\
$\operatorname{Corr}\left(\operatorname{err}_{t+1}, \operatorname{err}_{t-1}\right)$ & -0.01 & 0.11 & 0.36 \\
\hline
\end{tabular}

Note: Model statistics are computed from a 15,000 period simulation. $\mathrm{RE}=$ rational expectations, Near-RE = near-rational expectations, MAE = moving-average expectations.

Table 3 summarizes the quantitative properties of the representative agent's forecast errors under each of the three expectations regimes. The percentage forecast error for the composite variable $z_{t+1}$ is given by

$$
\operatorname{err}_{t+1}=\log \left(\frac{z_{t+1}}{\widehat{E}_{t} z_{t+1}}\right) .
$$

All three expectation regimes deliver unbiased forecasts such that Mean $\left(e r r_{t+1}\right)=0$. The 

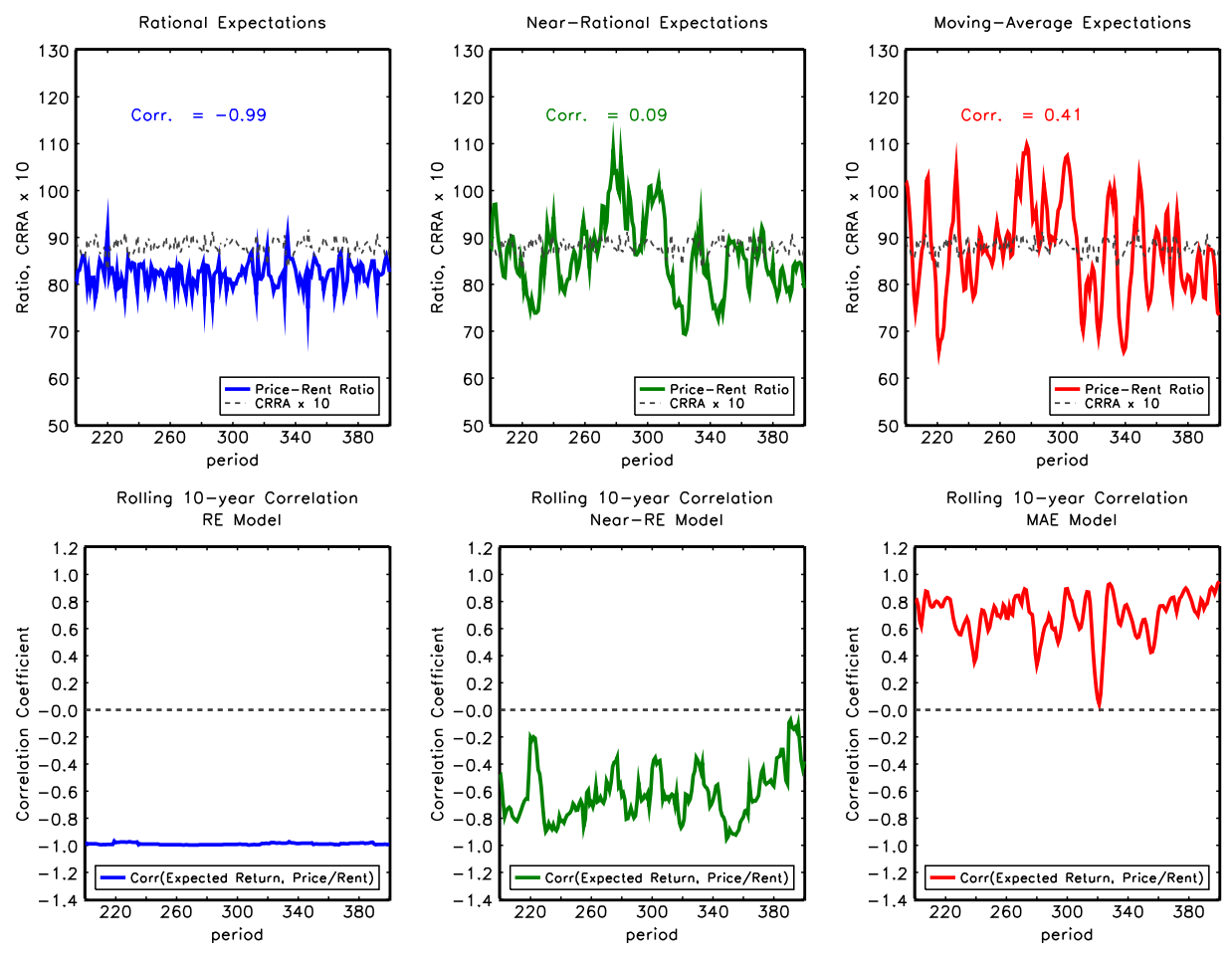

Figure 9: Correlation between expected housing returns and the price-rent ratio. Under rational expectations, the correlation coefficient between the price-rent ratio and the coefficient of relative risk aversion is close to -1 , implying that risk aversion is low when the price-rent ratio is high, and vice versa. The bottom panels show that under rational and near-rational expectations, the rolling correlation coefficient between the expected 4-quarter compound return and the price-rent ratio is strongly negative. However, the rolling correlation coefficient is typically positive under moving-average expectations, implying that agents tend to expect high future returns when the price-rent ratio is high, consistent with the survey evidence.

accuracy of each forecast rule can be measured by the root mean squared percentage error (RMSPE), defined as $\sqrt{\text { Mean }\left(e r r_{t+1}^{2}\right)}$. The rational expectations model exhibits the lowest RMSPE whereas the moving-average model exhibits the highest RMSPE. It is important to recognize, however, that an individual atomistic agent could not do better in the movingaverage model by switching to the fundamentals-based forecast rule derived in the rational expectations model. When the actual law of motion for the composite variable $z_{t}$ is given by (23), the fundamentals-based forecast rule is no longer the most accurate forecast. In particular, using the fundamentals-based forecast rule from the rational expectations model to predict $z_{t+1}$ in the moving-average model delivers a RMSPE of 0.186 - considerably higher than the value of 0.074 delivered by the moving-average forecast rule itself (24). Hence an individual atomistic agent can become "locked-in" to the use of a moving-average forecast rule 
so long as other agents in the economy are using the same forecasting approach. ${ }^{21}$

Table 3 also shows that the autocorrelation of the forecast errors in both the near-rational model and moving-average model are reasonably low-less than 0.4. Hence, a large amount of data would be required for the representative agent in either model to reject the null hypothesis of uncorrelated forecast errors, making it difficult for the agent to detect a misspecification of the subjective forecast rule.

Figure 8 shows how some key parameter values affect the volatility of the model price-rent ratio under each expectation regime. The dashed horizontal line in each panel marks the observed standard deviation of 13.65 in U.S. data. In the top left panel, we examine the effect of varying the utility curvature parameter $\alpha$ over the range $0 \leq \alpha \leq 3$ while holding $\theta$ and $\kappa$ at the baseline values shown in Table 1 . From equation (26) with $x_{t}=E\left(x_{t}\right)$, we have $\mathrm{CRRA}_{t}$ $=0.13$ when $\alpha=0$ and $\mathrm{CRRA}_{t}=13.1$ when $\alpha=3$. In the top right panel, we examine the effect of varying the habit formation parameter $\kappa$ over the range $0 \leq \kappa \leq 0.975$ while holding $\theta$ and $\alpha$ at the baseline values shown in Table 1 . In this case, the implied value of $\mathrm{CRRA}_{t}$ with $x_{t}=E\left(x_{t}\right)$ ranges from a low of 1.9 to a high of 64 . The top right panel shows that the rational expectations model can match the observed volatility in the data when $\kappa \simeq 0.945$, which together with the baseline values of $\theta=0.87$ and $\alpha=2$ delivers CRRA $_{t} \simeq 30$ when $x_{t}=E\left(x_{t}\right)$.

The bottom two panels of Figure 8 show that lower values of $T_{w}$ (near-rational model) or higher values of $\lambda$ (moving-average model) both serve to magnify the volatility of the simulated price-rent ratio. By construction, the baseline calibrated values of $T_{w}=16$ quarters and $\lambda=0.94$ deliver price-rent ratio volatilities that are close to those in the data.

Table 4 compares unconditional moments from the model to the corresponding moments in U.S. data. The near-rational model and the moving-average model are both successful in matching the volatility and persistence of the U.S. price-rent ratio. However, only the moving-average model comes close to matching the strong persistence of U.S. housing returns, delivering an autocorrelation coefficient for returns of 0.63 versus 0.59 in the data. Unfortunately, none of the three expectation regimes can reproduce the strong negative skewness and the large excess kurtosis of U.S. housing returns. The consideration of additional nonlinearities, such as endogenous shifts between forecast rules, along the lines of Brock and Hommes (1998), might allow the model to better match the higher return moments in the data.

\footnotetext{
${ }^{21}$ Lansing (2006) investigates the concept of forecast lock-in using a standard Lucas-type asset pricing model.
} 
Table 4. Unconditional Moments: Data versus Model

\begin{tabular}{lccccc}
\hline \hline & & U.S. Data & \multicolumn{3}{c}{ Model Simulations } \\
& Statistic & 1960.Q2-2013.Q3 & RE & Near-RE & MAE \\
\cline { 2 - 6 } & Mean & 82.3 & 82.3 & 84.6 & 85.9 \\
Price & Std. Dev. & 13.65 & 2.86 & 13.03 & 13.57 \\
Rent & Corr. Lag 1 & 0.99 & 0.46 & 0.96 & 0.95 \\
& Skewness & 2.01 & 0.37 & 0.27 & 0.00 \\
& Kurtosis & 7.05 & 4.37 & 3.26 & 3.10 \\
\cline { 2 - 6 } Real & Mean & $1.63 \%$ & $1.54 \%$ & $1.54 \%$ & $1.56 \%$ \\
Return & Std. Dev. & $1.60 \%$ & $4.07 \%$ & $4.07 \%$ & $4.82 \%$ \\
& Corr. Lag 1 & 0.59 & -0.22 & 0.27 & 0.63 \\
& Skewness & -1.13 & 0.31 & 0.29 & -0.11 \\
& Kurtosis & 7.77 & 4.26 & 3.23 & 3.40 \\
\hline
\end{tabular}

Note: Model statistics are computed from a 15,000 period simulation. RE = rational expectations, Near-RE $=$ near-rational expectations, MAE = moving-average expectations.

The top panels of Figure 9 show the correlations between the model price-rent ratios and the coefficient of relative risk aversion computed from equation (26). Under rational expectations, the correlation coefficient is close to -1 , implying that risk aversion is low when the price-rent ratio is high, and vice versa. Under near-rational expectations, the correlation coefficient is close to zero at 0.09. Under moving-average expectations, the correlation coefficient is positive at 0.41 .

The bottom panels of Figure 9 illustrate a key distinguishing feature of the three expectation regimes, namely, the correlation between the agent's conditional forecast of the 4-quarter compound return $\widehat{E}_{t}\left[r_{t+1 \rightarrow t+4}\right]$ and the current price-rent ratio $p_{t} / n_{t}$. We plot rolling correlation coefficients over a 10-year sample window to roughly capture the time duration of the recent boom-bust cycle in the U.S. housing market. Under rational expectations (bottom left panel), the rolling 10-year correlation remains close to -1 , implying that expected returns are low when the price-rent ratio is high - a feature that is directly at odds with the survey evidence. The near-rational model (bottom center panel) suffers from a similar problemexhibiting a rolling 10-year correlation that is always in negative territory, averaging around -0.7 over the full simulation. However, the moving-average model (bottom right panel) delivers a rolling 10-year correlation that is typically positive, averaging around 0.6 over the full simulation. In this case, agents tend to expect high future returns when the price-rent ratio is high, consistent with the survey evidence. Although not shown, the rolling 10-year correlation coefficient between the expected 8-quarter compound return and the price-rent ratio in the moving-average model is even higher, averaging close to 0.7 over the full simulation. The corresponding correlation coefficients in the rational and near-rational models remain strongly negative.

Figure 10 plots simulated house prices (in logarithms) under rational expectations and moving-average expectations, together with the common simulated rent series. The moving- 


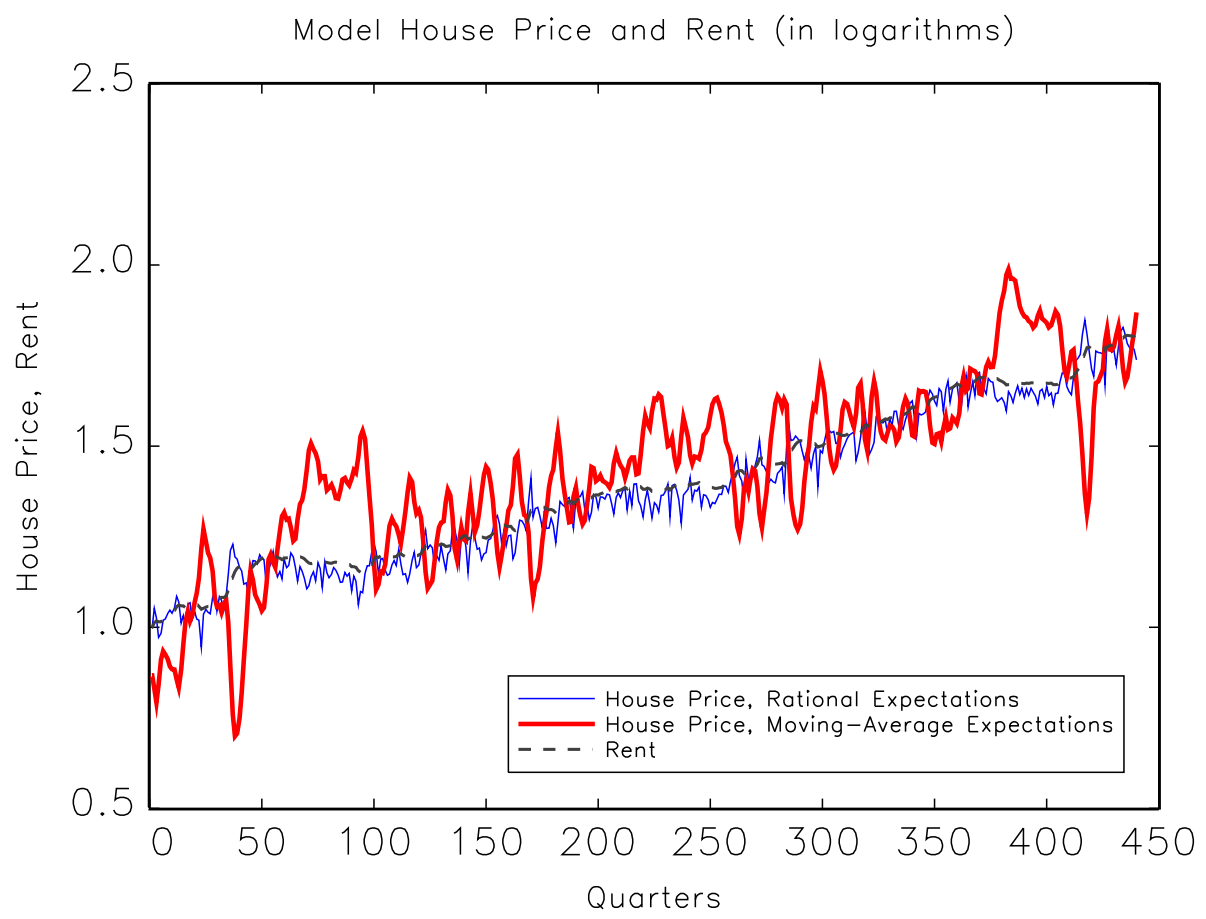

Figure 10: Real house prices and rent from model simulations. The moving-average model delivers periods of relatively stagnant real house prices interspersed with booms and busts, reminiscent of the long-run house price data plotted in Figure 1.

average model delivers periods of relatively stagnant real house prices interspersed with booms and busts, reminiscent of the long-run house price data plotted earlier in Figure 1.

As mentioned in the introduction, standard DSGE models with housing typically postulate large and persistent exogenous shocks to rational agents' preferences for housing services in an effort to magnify the volatility of house prices generated by the model. Table 5 shows the effects of a permanent upward shift in the agent's preference for housing services $h_{t}$ relative to consumption $c_{t}$. The preference shift is accomplished by reducing the parameter $\theta$ in the utility function (1) from the baseline value of 0.87 to a new value of 0.5 , while holding other parameters constant at the baseline values shown in Table 1 . After the preference shift, the relative weight on housing services $1-\theta$ is roughly quadrupled from the baseline value of 0.13 to a new value of 0.5 . Table 5 shows that an upward shift in the agent's preference for housing raises the mean price-rent ratio under all three expectations regimes. At the same time, the preference shift lowers the mean realized return on housing and lowers the mean value of $\mathrm{CRRA}_{t}$. Under rational expectations, the agent will take this relationship into account when forecasting such that the conditional expected return on housing, $E_{t}\left[r_{t+1 \rightarrow t+4}\right]$ will tend to move in the opposite direction as the price-rent ratio $p_{t} / n_{t}$ in response to a persistent shift 
in housing preferences. Hence, while a fully-rational model with housing preference shocks could potentially match the volatility of the price-rent ratio in the data, such a model would still predict a negative correlation between the expected return on housing and the price-rent ratio, which is contrary to the survey evidence described in section 2 .

The relatively flat trajectory of U.S. housing rents during boom years of the mid-2000s (top left panel of Figure 4) provides further evidence against a preference-driven run-up in house prices. From the first-order condition (4), we see that a sustained increase in housing preference, as measured by $1-\theta$, would give rise to a sustained increase in the imputed rent $n_{t}$, i.e., something which is not observed in the U.S. data during the boom years.

Table 5. Effect of a Permanent Increase in Housing Preference

\begin{tabular}{cccll}
\hline \hline $\begin{array}{c}\text { Housing } \\
\text { Preference } \\
1-\theta\end{array}$ & & \multicolumn{3}{c}{ Model Simulations } \\
\hline \multirow{2}{*}{0.13} & Means & \multicolumn{1}{c}{$\mathrm{RE}$} & Near-RE & MAE \\
& $p_{t} / n_{t}$ & 82.3 & 84.6 & 85.9 \\
& $r_{t+1 \rightarrow t+4}$ & $5.80 \%$ & $5.78 \%$ & $5.73 \%$ \\
& CRRA $_{t}$ & 8.8 & 8.8 & 8.8 \\
& & & \\
0.5 & $p_{t} / n_{t}$ & 88.4 & 89.4 & 89.8 \\
& $r_{t+1 \rightarrow t+4}$ & $5.46 \%$ & $5.41 \%$ & $5.43 \%$ \\
CRRA $_{t}$ & 5.5 & 5.5 & 5.5 \\
\hline
\end{tabular}

Note: Model statistics are computed from a 15,000 period simulation. $\mathrm{RE}=$ rational

expectations, Near-RE $=$ near-rational expectations, $\mathrm{MAE}=$ moving-average expectations.

\subsection{Predictability Regressions}

Campbell and Shiller (1988) show that a log-linear approximation of the stock market return identity implies that the variance of the log price-dividend ratio must equal the sum of the ratio's covariances with: (1) future dividend growth rates, and (2) future realized stock market returns. Applying the Campbell-Shiller methodology to the housing market return identity $R_{t+1} \equiv p_{t+1} /\left(p_{t}-n_{t}\right)=\left(p_{t+1} / n_{t+1}\right) \exp \left(x_{t+1}\right) /\left(p_{t} / n_{t}-1\right)$ yields

$$
\begin{aligned}
\log \left(R_{t+1}\right) & =\log \left(p_{t+1} / n_{t+1}\right)-\log \left(p_{t} / n_{t}-1\right)+x_{t+1} \\
& \simeq \delta_{0}+\log \left(p_{t+1} / n_{t+1}\right)-\delta_{1} \log \left(p_{t} / n_{t}\right)+x_{t+1},
\end{aligned}
$$

where $\delta_{0}$ and $\delta_{1}$ are Taylor series coefficients. Solving for $\log \left(p_{t} / n_{t}\right)$ yields

$$
\log \left(p_{t} / n_{t}\right) \simeq\left(\delta_{0} / \delta_{1}\right)+\left(1 / \delta_{1}\right) \log \left(p_{t+1} / n_{t+1}\right)+\left(1 / \delta_{1}\right) x_{t+1}-\left(1 / \delta_{1}\right) \log \left(R_{t+1}\right),
$$

where $\delta_{1}=\exp \left[E \log \left(p_{t} / n_{t}\right)\right] /\left\{\exp \left[E \log \left(p_{t} / n_{t}\right)\right]-1\right\}>1$ such that $1 / \delta_{1}<1$. The next step is to iterate equation (29) forward and successively eliminate $\log \left(p_{t+j} / n_{t+j}\right)$ for $j=1,2,3, \ldots$ 
Applying a transversality condition such that $\lim _{j \rightarrow \infty}\left(1 / \delta_{1}\right)^{j} \log \left(p_{t+j} / n_{t+j}\right)=0$ yields

$$
\log \left(p_{t} / n_{t}\right) \simeq \frac{\delta_{0}}{\delta_{1}-1}+\sum_{j=1}^{\infty}\left(1 / \delta_{1}\right)^{j}\left[x_{t+j}-\log \left(R_{t+j}\right)\right]
$$

which shows that movements in the log price-rent ratio must be accounted for by movements in either future rent growth rates or future log housing returns (both measured in real terms).

The variables in the approximate return identity (30) can be expressed as deviations from their unconditional means, while the means are consolidated into the constant term. Multiplying both sides of the resulting expression by $\log \left(p_{t} / n_{t}\right)-E \log \left(p_{t} / n_{t}\right)$ and then taking the unconditional expectation of both sides yields

$$
\begin{aligned}
\operatorname{Var}\left(p_{t} / n_{t}\right)= & \operatorname{Cov}\left[\log \left(p_{t} / n_{t}\right), \sum_{j=1}^{\infty}\left(1 / \delta_{1}\right)^{j} x_{t+j}\right] \\
& -\operatorname{Cov}\left[\log \left(p_{t} / n_{t}\right), \sum_{j=1}^{\infty}\left(1 / \delta_{1}\right)^{j} \log \left(R_{t+j}\right)\right] .
\end{aligned}
$$

Equation (31) states that the variance of the log price-rent ratio must be accounted for by the covariance of the log price-rent ratio with either: (1) future rent growth rates, or (2) future realized housing returns. The magnitude of each covariance term is a measure of the predictability of future rent growth or future realized returns when the current price-rent ratio is employed as the sole regressor in a forecasting equation.

To investigate the predictability implications of our model versus those in the data, we estimate the following regression equations:

$$
\begin{aligned}
& r_{t+1 \rightarrow t+4} \equiv \sum_{j=1}^{4} \log \left(R_{t+j}\right)=\text { constant }+\widehat{b} \log \left(p_{t} / n_{t}\right)+u_{t+1}, \\
& x_{t+1 \rightarrow t+4} \equiv \sum_{j=1}^{4} x_{t+j}=\text { constant }+\widehat{b} \log \left(p_{t} / n_{t}\right)+\omega_{t+1},
\end{aligned}
$$

where $u_{t+1}$ and $\omega_{t+1}$ are statistical error terms.

Table 6 reports the results of predictability regressions in the form of equations (32) or (33). In the case of the U.S. stock market, it is well documented that the log price-dividend ratio exhibits strong predictive power for future realized stock returns but weak predictive power for future dividend growth rates (Cochrane 2008, Engsted, et al. 2012). Table 6 shows that analogous results are obtained for the U.S. housing market, particularly in the more recent sample period starting in the year 2000. The $R^{2}$ statistic is much larger in the regression that seeks to predict future returns versus the regression that seeks to predict future rent growth. In the return regression (top panel of Table 6 ), the estimated coefficient $\widehat{b}$ is consistently large and negative, implying that a higher price-rent ratio predicts lower realized returns in the future. In the rent growth regression (bottom panel of Table 6 ), $\widehat{b}$ is negative and significant over the full sample starting in 1960, but insignificant and very close to zero in the more recent sample starting in the year 2000 . 
For the models, Table 6 reports results for two values for the utility curvature parameter $\alpha$ while holding $\theta$ and $\kappa$ at the baseline values shown in Table 1. From equation (26) with $x_{t}=E\left(x_{t}\right)$, we have $\mathrm{CRRA}_{t}=8.8$ when $\alpha=2$ (baseline calibration) and $\mathrm{CRRA}_{t}=2.3$ when $\alpha=0.5$ (alternative calibration).

All of the models produce a negative and significant value of $\widehat{b}$ in the first regression that seeks to predict future returns. The magnitude of the $\widehat{b}$ coefficients produced by the nearrational model $(-0.284$ or -0.252$)$ and the moving-average model $(-0.454$ or -0.437$)$ are reasonably close to those in the data $(-0.183$ or -0.278$)$. In contrast, the magnitude of the $\widehat{b}$ coefficients produced by the rational expectations model $(-0.895$ or -0.603$)$ are much larger than those in the data. With a few exceptions, the $R^{2}$ statistics in the model regressions are reasonably close to those in the data. The model calibration with $\alpha=0.5$ delivers somewhat lower $R^{2}$ statistics in the return regression since this value implies a less volatile stochastic discount factor and hence less movement in the dependent variable, $r_{t+1 \rightarrow t+4}$.

The intuition for the predictability of realized returns in both the data and the model is straightforward. A high price-rent ratio implies that the ratio is more likely to be above its long-run mean. If the price-rent ratio is stationary, then the ratio will eventually revert to its long-run mean. The inevitable drop in the price-rent ratio over a long horizon produces a lower realized return. Interestingly, even though a higher price-rent ratio in the data predicts lower realized returns, the survey evidence shows that real-world investors fail to take this relationship into account; instead they continue to forecast high future returns following a sustained run-up in the price-rent ratio, consistent with a moving-average forecast rule.

In sharp contrast to the U.S. data, the rational expectations model produces a large positive and significant value of $\widehat{b}$ in the regression that seeks to predict future rent growth. This is to be expected since time-varying rent growth (together with time-varying risk aversion) is an important fundamental driver of house prices under rational expectations. Similar to the U.S. data, both the near-rational model and the moving-average model produce small estimated coefficients in the rent growth regression. Moreover, the sign of $\widehat{b}$ in both models can be either positive or negative, depending on the calibrated value of $\alpha$. Lower values of $\alpha$ (implying lower risk aversion on average) produce positive values of $\widehat{b}$.

Equation (7) provides some intuition for why the rent growth regression coefficient $\widehat{b}$ can be either positive or negative in the near-rational and moving-average models, depending on the value of the utility curvature parameter $\alpha$. In both models, the agent's forecast is based on recent observations, not the true underlying laws of motion for the relevant variables. Hence, the agent does not properly take into account how a shock innovation at time $t+1$ will influence future rent growth rates and future price-rent ratios. The value of $\alpha$ is important because it governs the relative magnitude of the income and substitution effects of a shock to rent growth. This can be seen from the term $\exp \left\{[\theta(1-\alpha)] x_{t+1}\right\}$ that appears on the right side of equation (7). When $\alpha>1$, an increase in $x_{t+1}$ contributes to a lower price-rent ratio $p_{t} / n_{t}$ but the effect is reversed when $\alpha<1$. A fully-rational agent would take into account that the increase 
in $x_{t+1}$ also serves to increase $p_{t+1} / n_{t+1}$, but that forecast channel is distorted in the nearrational and moving-average models. Consequently, the term involving $\exp \left\{[\theta(1-\alpha)] x_{t+1}\right\}$ tends to dominate the sign of the rent growth regression coefficient in these two models. In contrast, the return regression coefficient exhibits a consistent negative sign across all models, regardless of the value of $\alpha$, because the sign of the coefficient is driven by the mean-reverting properties of the price-rent ratio.

In a recent study using price and rent data from the housing markets of 18 OECD countries over the period 1970 to 2011, Engsted and Pedersen (2012) find evidence of cross-country and sub-sample instability in the estimated coefficients for predictive regressions that take the form of equations (32) or (33). Using data either before or after 1995, they find that the estimated regression coefficients for a given country can be either positive or negative when predicting future rent growth along the lines of equation (33). Table 6 confirms a similar sort of instability in the sign of $\widehat{b}$ when attempting to predict future U.S. rent growth using either the full sample of data from 1960 to 2011 or the more recent sample from 2000 to 2011. Engsted and Pedersen (2012) also find that the relative magnitude of the $R^{2}$ statistics for the two types of predictive regressions can differ across countries and across time periods for a given country. In line with their overall empirical findings, our simulation results show that, depending on the nature of the expectation regime and the degree of curvature in the agent's utility function, the signs and magnitudes of the estimated regression coefficients and the resulting $R^{2}$ statistics can vary substantially, particularly with respect to rent growth predictability.

Table 6. Predictability Regressions: Data versus Model

\begin{tabular}{|c|c|c|c|c|c|c|c|c|}
\hline \multirow[b]{3}{*}{$\begin{array}{l}\text { Predictive } \\
\text { Regression }\end{array}$} & & & \multicolumn{6}{|c|}{ Model Simulations } \\
\hline & \multicolumn{2}{|c|}{$\underset{\widehat{b}}{\text { U.S. Data }}$} & \multicolumn{2}{|c|}{$\underset{\widehat{b}}{\mathrm{RE}}$} & \multicolumn{2}{|c|}{$\begin{array}{c}\text { Near-RE } \\
\widehat{b}\end{array}$} & \multicolumn{2}{|c|}{$\underset{\widehat{b}}{\mathrm{MAE}}$} \\
\hline & $\begin{array}{l}\text { 1960.Q2- } \\
\text { 2013.Q3 }\end{array}$ & $\begin{array}{l}\text { 2000.Q1- } \\
\text { 2013.Q3 }\end{array}$ & $\alpha=2$ & $\alpha=0.5$ & $\alpha=2$ & $\alpha=0.5$ & $\alpha=2$ & $\alpha=0.5$ \\
\hline$r_{t+1 \rightarrow t+4}$ & $\begin{array}{l}-0.183 \\
(0.024)\end{array}$ & $\begin{array}{l}-0.278 \\
(0.077)\end{array}$ & $\begin{array}{l}-0.895 \\
(0.011)\end{array}$ & $\begin{array}{c}-0.603 \\
(0.017)\end{array}$ & $\begin{array}{l}-0.284 \\
(0.005)\end{array}$ & $\begin{array}{l}-0.252 \\
(0.006)\end{array}$ & $\begin{array}{l}-0.453 \\
(0.006)\end{array}$ & $\begin{array}{l}-0.437 \\
(0.008)\end{array}$ \\
\hline$R^{2}(\%)$ & 21.4 & 21.3 & 31.7 & 7.8 & 19.7 & 9.2 & 30.1 & 17.0 \\
\hline$x_{t+1 \rightarrow t+4}$ & $\begin{array}{l}-0.039 \\
(0.007)\end{array}$ & $\begin{array}{l}-0.001 \\
(0.014)\end{array}$ & $\begin{array}{c}0.111 \\
(0.004)\end{array}$ & $\begin{array}{c}0.398 \\
(0.011)\end{array}$ & $\begin{array}{l}-0.002 \\
(0.001)\end{array}$ & $\begin{array}{c}0.021 \\
(0.002)\end{array}$ & $\begin{array}{l}-0.008 \\
(0.001)\end{array}$ & $\begin{array}{c}0.026 \\
(0.001)\end{array}$ \\
\hline$R^{2}(\%)$ & 11.9 & 0.0 & 5.8 & 8.5 & 0.0 & 1.2 & 0.8 & 2.3 \\
\hline
\end{tabular}

Notes: Standard errors in parenthesis. Model regressions use data from a 15,000 period simulation. RE $=$ rational expectations, Near-RE =near-rational expectations, MAE = moving-average expectations. Returns and rent growth in U.S. data are measured in real terms. 


\section{Conclusion}

Stories involving speculative bubbles can be found throughout history in various countries and asset markets. These episodes can have important consequences for the economy as firms and investors respond to the price signals, potentially resulting in capital misallocation. ${ }^{22}$ The typical transitory nature of these run-ups should perhaps be viewed as a long-run victory for fundamental asset pricing theory. Still, it remains a challenge for fundamental theory to explain the ever-present volatility of asset prices within a framework of efficient markets and fully-rational agents.

Like stock prices, real-world house prices exhibit periods of stagnation interspersed with boom-bust cycles. A reasonably-parameterized rational expectations model significantly underpredicts the volatility of the U.S. price-rent ratio, even when allowing for time-varying risk aversion and time-varying stochastic properties of rent growth. We showed that a standard asset pricing model can match the volatility and persistence of the U.S. price-rent ratio, as well as other quantitative and qualitative features of the data, if agents in the model employ simple moving-average forecast rules. With such a forecast rule, agents tend to expect higher future returns when house prices are high relative to fundamentals - a feature that is consistent with survey evidence on the expectations of real-world housing investors. The moving average model is also successful in generating data that is broadly consistent with the predictability properties of future realized housing returns and future rent growth that are observed in housing market data for the U.S. and other countries.

\footnotetext{
${ }^{22}$ Lansing (2012) examines the welfare consequences of speculative bubbles in a model where excessive asset price movements can affect the economy's trend growth rate.
} 


\section{A Appendix: Effect of a Borrowing Constraint}

Here we show analytically how imputed rent can reflect not only a utility dividend, but also the marginal collateral value of the house in the case when the representative agent's borrowing constraint is binding. Following Campbell and Hercowitz (2009), the representative agent's problem in the presence of a borrowing constraint can be formulated as

$$
\max _{c_{t}, h_{t}, b_{t+1}} \widehat{E}_{0} \sum_{t=0}^{\infty} \beta^{t} £_{t},
$$

where the current-period Lagrangian $£_{t}$ is given by

$$
\begin{array}{cl}
£_{t}=\frac{\left(c_{t}^{\theta} h_{t}^{1-\theta}-\kappa C_{t-1}^{\theta} H_{t-1}^{1-\theta}\right)^{1-\alpha}-1}{1-\alpha} & +\lambda_{t}\left[y_{t}+b_{t+1}+p_{t}\left(h_{t-1}-h_{t}\right)-c_{t}-R b_{t}\right] \\
& +\lambda_{t} \mu_{t}\left[\omega p_{t} h_{t}-b_{t+1}\right] .
\end{array}
$$

In the above expression, $b_{t+1}$ is the stock of mortgage debt at the end of period $t$ and $R$ is the gross real interest rate on the debt. The last term of the Lagrangian reflects the borrowing constraint which says that the agent may only borrow up to a fraction $\omega \geq 0$ of the current housing value $p_{t} h_{t}$. When the Lagrange multiplier $\mu_{t}>0$, the borrowing constraint is binding.

From (A.2), the first-order conditions with respect to $h_{t}$ and $b_{t+1}$ are given by

$$
\begin{aligned}
& p_{t}=\underbrace{\left(\frac{1-\theta}{\theta}\right) c_{t}+\mu_{t} \omega p_{t}}_{\equiv n_{t}}+\widehat{E}_{t} \underbrace{\frac{\lambda_{t+1}}{\lambda_{t}}}_{\equiv M_{t+1}} p_{t+1}, \\
& \mu_{t}=1-\beta R E_{t} M_{t+1},
\end{aligned}
$$

where we have divided both sides by $\lambda_{t}$ and imposed the equilibrium condition $h_{t}=1$. Comparing equation (A.3) to the original first-order condition (4) shows that the imputed rent $n_{t}$ now consists of two terms: the standard utility dividend plus the marginal collateral value of the house in the case when the borrowing constraint is binding, i.e., when $\mu_{t}>0$. Hence, by calibrating the effective cash flows in the model to mimic the stochastic properties of rent

growth in the data, we implicitly (but imperfectly) take into account the effect of a binding borrowing constraint on the equilibrium house price.

\section{B Appendix: Approximate Rational Solution}

The methodology for computing the rational expectations solution in Proposition 1 follows the procedure in Lansing (2010). First we rewrite the law of motion for rent growth (5) as 
follows

$$
\begin{aligned}
x_{t+1}-E\left(x_{t}\right) & =\rho\left[x_{t}-E\left(x_{t}\right)\right]+(1-\rho) \underbrace{\left[\bar{x}-E\left(x_{t}\right)\right]}_{=\frac{-\psi \sigma_{\varepsilon}^{2}}{1-\rho}}+\varepsilon_{t+1}+\psi \underbrace{\varepsilon_{t}\left(x_{t}-\bar{x}\right)}_{\equiv v_{t}}, \\
& =\rho\left[x_{t}-E\left(x_{t}\right)\right]+\varepsilon_{t+1}+\psi\left(v_{t}-\sigma_{\varepsilon}^{2}\right),
\end{aligned}
$$

where $\bar{x}$ is the deterministic steady state growth rate, $E\left(x_{t}\right)$ is the ergodic mean growth rate, and we have made use of $E\left[\varepsilon_{t}\left(x_{t}-\bar{x}\right)\right]=E\left(v_{t}\right)=\sigma_{\varepsilon}^{2}$.

The law of motion for $v_{t+1}-\sigma_{\varepsilon}^{2}$ follows directly from the law of motion for rent growth (5) and the rewritten version (B.1):

$$
\begin{aligned}
v_{t+1}-\sigma_{\varepsilon}^{2} & =\varepsilon_{t+1}\left(x_{t+1}-\bar{x}\right)-\sigma_{\varepsilon}^{2}, \\
& =\varepsilon_{t+1}\left[x_{t+1}-E\left(x_{t}\right)\right]+\varepsilon_{t+1} \underbrace{\left[E\left(x_{t}\right)-\bar{x}\right]}_{=\frac{\psi \sigma_{\varepsilon}^{2}}{1-\rho}}-\sigma_{\varepsilon}^{2}, \\
& =\varepsilon_{t+1}\left\{\rho\left[x_{t}-E\left(x_{t}\right)\right]+\psi\left(v_{t}-\sigma_{\varepsilon}^{2}\right)+\frac{\psi \sigma_{\varepsilon}^{2}}{1-\rho}\right\}+\left(\varepsilon_{t+1}^{2}-\sigma_{\varepsilon}^{2}\right),
\end{aligned}
$$

Iterating ahead the conjectured law of motion for $z_{t}$ yields

$$
z_{t+1}=a_{0} \exp \left\{a_{1}\left[x_{t+1}-E\left(x_{t}\right)\right]+a_{2}\left(v_{t+1}-\sigma_{\varepsilon}^{2}\right)\right\} \text {. }
$$

Substituting equations (B.1) and (B.2) into equation (B.3) and then taking the conditional expectation yields

$$
E_{t} z_{t+1}=a_{0} \exp \left\{a_{1} \rho\left[x_{t}-E\left(x_{t}\right)\right]+a_{1} \psi\left(v_{t}-\sigma_{\varepsilon}^{2}\right)+\left(a_{2}\right)^{2} \sigma_{\varepsilon}^{4}+\frac{1}{2} w_{t}^{2} \sigma_{\varepsilon}^{2}\right\},
$$

where $\quad w_{t} \equiv a_{1}+a_{2} \rho\left[x_{t}-E\left(x_{t}\right)\right]+a_{2} \psi\left(v_{t}-\sigma_{\varepsilon}^{2}\right)+a_{2} \frac{\psi \sigma_{\varepsilon}^{2}}{1-\rho}$.

In deriving (B.4), we have used the properties of the conditional lognormal distribution which imply

$$
\begin{aligned}
E_{t} \exp \left(a_{2} \varepsilon_{t+1}^{2}\right) & =\exp \left\{E_{t}\left(a_{2} \varepsilon_{t+1}^{2}\right)+\frac{1}{2} \operatorname{Var}_{t}\left(a_{2} \varepsilon_{t+1}^{2}\right)\right\} \\
& =\exp \left\{E_{t}\left(a_{2} \varepsilon_{t+1}^{2}\right)+\frac{1}{2} E_{t}\left[\left(a_{2} \varepsilon_{t+1}^{2}\right)^{2}\right]-\frac{1}{2}\left[E_{t}\left(a_{2} \varepsilon_{t+1}^{2}\right)\right]^{2}\right\} \\
& =\exp \left\{a_{2} \sigma_{\varepsilon}^{2}+\frac{1}{2}\left(a_{2}\right)^{2} 3 \sigma_{\varepsilon}^{4}-\frac{1}{2}\left(a_{2}\right)^{2} \sigma_{\varepsilon}^{4}\right\} \\
& =\exp \left[a_{2} \sigma_{\varepsilon}^{2}+\left(a_{2}\right)^{2} \sigma_{\varepsilon}^{4}\right] .
\end{aligned}
$$


Next, we substitute the conditional expectation (B.4) into the transformed first-order condition (8) and then take logarithms to obtain

$$
\begin{aligned}
\log \left(z_{t}\right)= & F\left(x_{t}, v_{t}\right)=\log \left\{g\left(x_{t}\right)+\right. \\
& \left.\beta a_{0} \exp \left[\theta(1-\alpha) x_{t}+a_{1} \rho\left[x_{t}-E\left(x_{t}\right)\right]+a_{1} \psi\left(v_{t}-\sigma_{\varepsilon}^{2}\right)+\left(a_{2}\right)^{2} \sigma_{\varepsilon}^{4}+\frac{1}{2} w_{t}^{2} \sigma_{\varepsilon}^{2}\right]\right\}, \\
\simeq & \log \left(a_{0}\right)+a_{1}\left[x_{t}-E\left(x_{t}\right)\right]+a_{2}\left(v_{t}-\sigma_{\varepsilon}^{2}\right) .
\end{aligned}
$$

The expressions for the Taylor-series coefficients $a_{0}=\exp \left[E \log \left(z_{t}\right)\right], a_{1}$, and $a_{2}$ are derived as follows

$$
\begin{aligned}
\log \left(a_{0}\right) & =F\left[E\left(x_{t}\right), E\left(v_{t}\right)\right] \\
a_{1} & =\left.\frac{\partial F}{\partial x_{t}}\right|_{E\left(x_{t}\right), E\left(v_{t}\right)}, \\
a_{2} & =\left.\frac{\partial F}{\partial v_{t}}\right|_{E\left(x_{t}\right), E\left(v_{t}\right)},
\end{aligned}
$$

where $E\left(x_{t}\right)=\bar{x}+\psi \sigma_{\varepsilon}^{2} /(1-\rho)$ and $E\left(v_{t}\right)=\sigma_{\varepsilon}^{2}$. Solving the above three equations yields the values for the three undetermined coefficients.

Taking logs of equation (B.3) and then forming the conditional expectation yields

$$
\begin{aligned}
E_{t} \log \left(z_{t+1}\right) & =\log \left(a_{0}\right)+a_{1} E_{t}\left[x_{t+1}-E\left(x_{t}\right)\right]+a_{2} E_{t}\left(v_{t+1}-\sigma_{\varepsilon}^{2}\right), \\
& =\log \left(a_{0}\right)+a_{1} \rho\left[x_{t}-E\left(x_{t}\right)\right]+a_{1} \psi\left(v_{t}-\sigma_{\varepsilon}^{2}\right),
\end{aligned}
$$

where $E_{t}\left(v_{t+1}-\sigma_{\varepsilon}^{2}\right)=0$ from equation (B.2). The above expression and equation (B.4) are used to compute the expected log return in equation (12).

\section{Appendix: Approximate Near-Rational Solution}

First we solve for the perceived rational solution in the case when the perceived AR(1) parameters for rent growth are constant such that $\bar{x}_{t}=\bar{x}, \gamma_{t}=\gamma$, and $\sigma_{\eta, t}=\sigma_{\eta}$ for all $t$. The near-rational agent's conjectured law of motion in this case is given by

$$
z_{t} \simeq b_{0} \exp \left[b_{1}\left(x_{t}-\bar{x}\right)\right]
$$

Iterating ahead the conjectured law of motion for $z_{t}$ and taking the subjective conditional expectation yields

$$
\widehat{E}_{t} z_{t+1}=b_{0} \exp \left[b_{1} \gamma\left(x_{t}-\bar{x}\right)+\frac{1}{2}\left(b_{1}\right)^{2} \sigma_{\eta}^{2}\right]
$$


Substituting the conditional forecast (C.2) into the transformed first-order condition (8) and then taking logarithms yields

$$
\begin{aligned}
\log \left(z_{t}\right) & =F\left(x_{t}\right)=\log \left\{g\left(x_{t}\right)+\beta b_{0} \exp \left[\theta(1-\alpha) x_{t}+b_{1} \gamma\left(x_{t}-\bar{x}\right)+\frac{1}{2}\left(b_{1}\right)^{2} \sigma_{\eta}^{2}\right]\right\} \\
& \simeq \log \left(b_{0}\right)+b_{1}\left(x_{t}-\bar{x}\right),
\end{aligned}
$$

where $b_{0} \equiv \exp [E \log (z)]$ and $b_{1}$ are Taylor-series coefficients. The expressions for the Taylor series coefficients are are derived as follows

$$
\begin{aligned}
\log \left(b_{0}\right) & =F(\bar{x})=\log \left\{g(\bar{x})+\beta b_{0} \exp \left[\theta(1-\alpha) \bar{x}+\frac{1}{2}\left(b_{1}\right)^{2} \sigma_{\eta}^{2}\right]\right\} \\
b_{1} & =F^{\prime}(\bar{x})=\frac{1}{b_{0}}\left\{g^{\prime}(\bar{x})+\beta b_{0}\left[\theta(1-\alpha)+b_{1} \gamma\right] \exp \left[\theta(1-\alpha) \bar{x}+\frac{1}{2}\left(b_{1}\right)^{2} \sigma_{\eta}^{2}\right]\right\}
\end{aligned}
$$

which yield a set of two equations that can be solved for the two undetermined coefficients $b_{0}$ and $b_{1}$.

For the case when the perceived $\mathrm{AR}(1)$ parameters are shifting as in the near-rational PLM (14), equations (C.4) and (C.5) can be rewritten as

$$
\begin{aligned}
b_{0, t} & =\frac{g\left(\bar{x}_{t}\right)}{1-\beta \exp \left[\theta(1-\alpha) \bar{x}_{t}+\frac{1}{2}\left(b_{1, t}\right)^{2} \sigma_{\eta, t}^{2}\right]}, \\
b_{1, t} & =\frac{g^{\prime}\left(\bar{x}_{t}\right)}{b_{0, t}}+\beta\left[\theta(1-\alpha)+b_{1, t} \gamma_{t}\right] \exp \left[\theta(1-\alpha) \bar{x}_{t}+\frac{1}{2}\left(b_{1, t}\right)^{2} \sigma_{\eta, t}^{2}\right],
\end{aligned}
$$

where we have substituted in the most recent estimates for the perceived $\operatorname{AR}(1)$ parameters, as given by $\bar{x}_{t}, \gamma_{t}$, and $\sigma_{\eta, t}$. We follow the common practice in the learning literature by assuming that the agent views the most recent parameter estimates as permanent when computing the subjective forecast $\widehat{E}_{t} z_{t+1}$. Given the most recent estimates for the $\operatorname{AR}(1)$ parameters, equations (C.6) and (C.7) are solved simultaneously each period to obtain values for $b_{0, t}$ and $b_{1, t}$ for use in the subjective forecast (19). The subjective forecast is substituted into the transformed first-order condition (8) to obtain the actual law of motion (20).

Iterating ahead the perceived law of motion (18) and then taking logs and forming the subjective conditional expectation yields

$$
\begin{aligned}
\widehat{E}_{t} \log \left(z_{t+1}\right) & =\widehat{E}_{t}\left[\log \left(b_{0, t+1}\right)+b_{1, t+1}\left(x_{t+1}-\bar{x}_{t+1}\right)\right] \\
& =\log \left(b_{0, t}\right)+b_{1, t} \gamma_{t}\left(x_{t}-\bar{x}_{t}\right)
\end{aligned}
$$

where once again we assume that the agent views the most recent parameter estimates $\bar{x}_{t}$ and $\gamma_{t}$ as permanent such that the most recent values for $b_{0, t}$ and $b_{1, t}$ are also viewed as permanent. The above expression and $\widehat{E}_{t} z_{t+1}$ from equation (19) are used to compute the expected log return in equation (21). 


\section{Appendix: Moments of Rent Growth}

This section summarizes the formulas for the unconditional moments of rent growth which are

used to calibrate the true law of motion (5). From Granger and Andersen (1978) and Sesay and Subba Rao (1988), we have

$$
\begin{aligned}
& E\left(x_{t}-\bar{x}\right) \equiv M_{1}=\frac{\psi \sigma_{\varepsilon}^{2}}{1-\rho} \\
& E\left[\left(x_{t}-\bar{x}\right)^{2}\right] \equiv M_{2}=\frac{\sigma_{\varepsilon}^{2}\left[1+2 \psi^{2} \sigma_{\varepsilon}^{2}+4 \rho \psi M_{1}\right]}{1-\rho^{2}-\psi^{2} \sigma_{\varepsilon}^{2}} \\
& E\left[\left(x_{t}-\bar{x}\right)\left(x_{t-1}-\bar{x}\right)\right] \equiv M_{1,1}=\rho M_{2}+2 \psi \sigma_{\varepsilon}^{2} M_{1} \\
& E\left[\left(x_{t}-\bar{x}\right)^{3}\right] \equiv M_{3}=\frac{\sigma_{\varepsilon}^{2}\left[6 \psi^{3} \sigma_{\varepsilon}^{4}+3\left(1+6 \rho \psi^{2} \sigma_{\varepsilon}^{2}\right) M_{1}+9 \psi\left(\rho^{2}+\psi^{2} \sigma_{\varepsilon}^{2}\right) M_{2}\right]}{1-\rho^{3}-3 \rho \psi^{2} \sigma_{\varepsilon}^{2}} \\
& E\left[\left(x_{t}-\bar{x}\right)^{4}\right] \equiv M_{4}=\frac{\sigma_{\varepsilon}^{2}\left\{3 \sigma_{\varepsilon}^{2}\left(8 \psi^{4} \sigma_{\varepsilon}^{4}-1\right)+96 \rho \psi^{3} \sigma_{\varepsilon}^{4} M_{1}+6\left[1+12 \psi^{2} \sigma_{\varepsilon}^{2}\left(\rho^{2}+\psi^{2} \sigma_{\varepsilon}^{2}\right)\right] M_{2}+16 \rho \psi\left(\rho^{2}+3 \psi^{2} \sigma_{\varepsilon}^{2}\right) M_{3}\right\}}{1-\rho^{4}-6 \rho^{2} \psi^{2} \sigma_{\varepsilon}^{2}-3 \psi^{4} \sigma_{\varepsilon}^{4}}
\end{aligned}
$$

Given the above expressions, the moments of $x_{t}$ can be computed as follows

$$
\begin{aligned}
E\left(x_{t}\right) & =\bar{x}+M_{1} \\
\operatorname{Var}\left(x_{t}\right) & =M_{2}-\left(M_{1}\right)^{2} \\
\operatorname{Corr}\left(x_{t}, x_{t-1}\right) & =\frac{M_{1,1}-\left(M_{1}\right)^{2}}{\operatorname{Var}\left(x_{t}\right)} \\
\operatorname{Skew}\left(x_{t}\right) & =\frac{M_{3}-\left(M_{1}\right)^{3}-3 M_{1} \operatorname{Var}\left(x_{t}\right)}{\operatorname{Var}\left(x_{t}\right)^{1.5}} \\
\operatorname{Kurt}\left(x_{t}\right) & =\frac{M_{4}+\left(M_{1}\right)^{4}-4 M_{1}\left[M_{3}+\left(M_{1}\right)^{3}\right]+6 M_{2}\left(M_{1}\right)^{2}}{\operatorname{Var}\left(x_{t}\right)^{2}} .
\end{aligned}
$$




\section{References}

Adam, K., Marcet, A., Nicolini, J.P., 2008. Stock market volatility and learning. European Central Bank, Working Paper 862

Adam, K., Kuang, P., Marcet A., 2012. House price booms and the current account. In Acemoglu, D., Woodford, M. (Eds.), NBER Macroeconomics Annual 2011. University of Chicago Press, Chicago, pp. 77-122.

Amromin, G., Sharpe, S.A., 2014. From the horse's mouth: Economic conditions and investor expectations of risk and return. Management Science 60, 845-866.

Ayuso, J., Restoy, F., 2006. House prices and rents: An equilibrium asset pricing approach. Journal of Empirical Finance 13, 371-388.

Barberis, N., Shleifer, A., Vishny, R.W., 1998. A model of investor sentiment. Journal of Financial Economics 49, 307-343.

Barsky, R.B., De Long, J.B., 1993. Why does the stock market fluctuate? Quarterly Journal of Economics 107, 291-311.

Branch, W.A., Evans, G.W., 2010. Asset return dynamics and learning. Review of Financial Studies 23, 1651-1680.

Brock, W.A., Hommes, C.H. 1998. Heterogenous beliefs and routes to chaos in a simple asset pricing model. Journal of Economic Dynamics and Control 22, 1235-1274.

Campbell, J.Y., Shiller, R.J., 1988. The dividend-price ratio and expectations of future dividends and discount factors. Review of Financial Studies 1, 195-228.

Campbell, J.Y., Cochrane, J.H., 1999. By force of habit: A consumption-based explanation of aggregate stock market behavior. Journal of Political Economy 107, 205-251.

Campbell. J.R., Hercowitz, Z., 2009. Welfare implications of the transition to high household debt. Journal of Monetary Economics 56, 1-16.

Campbell, S., Davis, M.A., Gallin, J., Martin, R.F., 2009. What moves housing markets: A variance decomposition of the price-rent ratio. Journal of Urban Economics 66, 90-102.

Case, K.E., Shiller, R.J., Thompson. A., 2012. What have they been thinking? Home buyer behavior in hot and cold markets. Brookings Papers on Economic Activity (Fall), 265-298.

Chow, G.C., 1989. Rational versus adaptive expectations in present value models. Review of Economics and Statistics 71, 385-393.

Cochrane, J.H., 2008. The dog that did not bark: A defense of return predictability. Review of Financial Studies 21, 1533-1575.

Cochrane, J.H., 2011. How did Paul Krugman get it so wrong? Economic Affairs 31, 36-40.

Coibion, O., Gorodnichencko, Y., 2012. What can survey forecasts tell us about informational rigidities? Journal of Political Economy 120, 116-159.

Collard, F., Juillard, M., 2001. Accuracy of stochastic perturbation methods: The case of asset pricing models. Journal of Economic Dynamics and Control 25, 979-999.

Collin-Dufresne, P., Johannes, M., Løchstøer, L.A., 2012. Parameter learning in general equilibrium: The asset pricing implications. Columbia Business School, Working paper.

Davis, M.A., Lehnert, A., Martin, R.F., 2008. The rent-price ratio for the aggregate stock of owner-occupied housing. Review of Income and Wealth 54, 279-284.

Dell'Ariccia, G., Igan, D., Laeven, L., 2012. Credit booms and lending standards: Evidence from the subprime mortgage market. Journal of Money Credit and Banking 44, 367-384. 
Doblas-Madrid, A., 2012. A robust model of bubbles with multidimensional uncertainty. Econometrica 80, 1845-1893.

Eitrheim, Ø., Erlandsen. S.K., 2004. House price indices for Norway 1819-2003. Norges Bank Occasional Paper 35, Chapter 9.

Eitrheim, Ø., Erlandsen, S.K., 2005. House prices in Norway 1819-1989. Scandinavian Economic History Review 53, 7-33. Updated data from www.norges-bank.no/en/price-stability/historicalmonetary-statistics/

Engsted, T., Pedersen, T.Q., Tanggaard, C., 2012. The log-linear return approximation, bubbles and predictability. Journal of Financial and Quantitative Analysis 47, 643-665.

Engsted, T., Pedersen, T.Q., 2012. Predicting returns and rent growth in the housing market using the rent-to-price ratio: Evidence from the OECD countries. Center for Research in Econometric Analysis of Time Series (CREATES), Aarhus University, Research paper 201258.

Evans, G.W., 1991. Pitfalls in testing for explosive bubbles in asset prices. American Economic Review 81, 922-930.

Evans, G.W., Honkapohja, S., 2001. Learning and expectations in economics. Princeton: Princeton University Press.

Evans, G.W., Ramey, G., 2006. Adaptive expectations, underparameterization, and the Lucas critique. Journal of Monetary Economics 53, 249-264.

Favilukis, J., Ludvigson, S., Van Niewerburgh, S., 2013. The macroeconomic effects of housing wealth, housing finance, and limited risk-sharing in general equilibrium. New York University, Working Paper.

Fisher, K.L., Statman. M., 2002. Blowing bubbles. Journal of Psychology and Financial Markets 3, 53-65.

Fuster, A., Hebert, B., Laibson, D., 2012. Natural expectations, macroeconomic dynamics, and asset pricing. In Acemoglu, D., Woodford, M. (Eds.), NBER Macroeconomics Annual 2011. University of Chicago Press, Chicago, pp. 1-48.

Goetzmann, W.N., Peng, L., Yen, J., 2012. The subprime crisis and house price appreciation. Journal of Real Estate Finance and Economics 44, 36-56.

Gelain, P., Lansing., K.J., Mendicino, C., 2013. House prices, credit growth, and excess volatility: Implications for monetary and macroprudential policy. International Journal of Central Banking 9(2), 219-276.

Granger, C.W.J., Andersen, A. P., 1978. An introduction to bilinear time series models. Vandenhoeck and Ruprecht, Göttingen.

Granziera, E., Kozicki, S., 2012. House price dynamics: Fundamentals and expectations. Bank of Canada Working Paper 2012-12.

Greenspan, A., 2004. The mortgage market and consumer debt, Remarks at Community Bankers Annual Convention. Washington D.C. (October 19).

Greenwood, R., Shleifer, A., 2013. Expectations of returns and expected returns. NBER Working Paper 18686.

Gudell, S., 2012. Comparing price-to-income ratios to affordability across markets. Zillow Real Estate Research (June 29).

Himmelberg, C., Mayer, C., Sinai, T., 2005. Assessing high house prices: Bubbles, fundamentals, and misperceptions. Federal Reserve Bank of New York, Staff Report Number 218 (September). 
Hommes, C., Sorger, G., 1998. Consistent expectations equilibria. Macroeconomic Dynamics $2,287-321$.

Hommes, C., Zhu, M., 2014. Behavioral learning equilibria. Journal of Economic Theory 150, 778-814.

Huang, K., Liu, Z., Zha, T., 2009. Learning, adaptive expectations, and technology shocks. Economic Journal 119, 377-405.

Huh, C.G., Lansing, K.J., 2000. Expectations, credibility, and disinflation in a small macroeconomic model. Journal of Economics and Business 52, 51-86.

Iacoviello, M., Neri, S., 2010. Housing market spillovers: Evidence from an estimated DSGE model. American Economic Journal: Macroeconomics 2, 125-164.

Jurgilas, M., Lansing, K.J., 2013. Housing bubbles and expected returns to home ownership: Lessons and policy implications. In Balling, M., Berg, J. (Eds.), Property Prices and Real Estate Financing in a Turbulent World. Société Universitaire Européenne de Recherches Financières (SUERF), Brussels/Vienna, 2013/4, pp. 101-128.

Knutsen, S., 2012. Why do banking crises occur? The American subprime crisis compared with the Norwegian banking crisis of 1987-92. Norges Bank Working Paper 2012/03.

Lansing K.J., 2006. Lock-in of extrapolative expectations in an asset pricing model. Macroeconomic Dynamics 10, 317-348.

Lansing, K.J., 2009. Time-varying U.S. inflation dynamics and the New Keynesian Phillips curve. Review of Economic Dynamics 12, 304-326.

Lansing, K.J., 2010. Rational and near-rational bubbles without drift. Economic Journal 120, 1149-1174.

Lansing, K.J., 2011. Gauging the impact of the great recession. Federal Reserve Bank of San Francisco Economic Letter 2011-21 (July 11).

Lansing, K.J. 2012 Speculative growth, overreaction, and the welfare cost of technology-driven bubbles, Journal of Economic Behavior and Organization 83, 461-483.

Lansing, K.J., LeRoy, S.F., 2014. Risk aversion, investor information, and stock market volatility. European Economic Review, forthcoming.

LeRoy, S.F., Porter, R.D., 1981. The present-value relation: Tests based on implied variance bounds. Econometrica 49, 555-577.

Levine, P., Pearlman, J., Perendia, G., Yang, B., 2012. Endogenous persistence in an estimated DSGE model under imperfect information. Economic Journal 122, 1287-1312.

Lucas, R.E., 1978. Asset prices in an exchange economy. Econometrica 46, 1429-1445.

Maurer, J., Meier, A.,2008. Smooth it like the Joneses: Estimating peer-group effects in intertemporal consumption choice. Economic Journal 118, 454-476.

Mehra, R., Prescott, E., 1985. The equity premium: A puzzle. Journal of Monetary Economics $14,145-161$.

Nerlove, M., 1983. Expectations, plans, and realizations in theory and practice. Econometrica $51,1251-1279$.

Otrok, C., Ravikumar, B., Whiteman, C.H., 2002. Habit formation: A resolution of the equity premium puzzle? Journal of Monetary Economics 49, 1261-1288.

Piazzesi, M., Schneider, M., Tuzel, S., 2007. Housing, consumption, and asset pricing. Journal of Financial Economics 83, 531-569. 
Piazzesi, M., Schneider, M., 2009. Momentum traders in the housing market: Survey evidence and a search model. American Economic Review Papers and Proceedings 99, 406-411.

Potter, S., 2011. The failure to forecast the Great Recession. Federal Reserve Bank of New York, Liberty Street Economics Blog (November 25).

Sargent, T.J., 1999. The Conquest of American Inflation. Princeton University Press, Princeton.

Sesay, S.A.O., Subba Rao, T., 1988. Yule-Walker type difference equations for higher order moments and cumulants for the bilinear time series models. Journal of Time Series Analysis 9, 385-401.

Shiller, R.J., 1981. Do stock prices move too much to be justified by subsequent changes in dividends? American Economic Review 71, 421-436.

Shiller, R.J., 2005. Irrational exuberance, 2nd Edition. Princeton University Press, Princeton. Updated data from http://www.econ.yale.edu/ shiller/data.htm

Shiller, R.J., 2008. Historic turning points in real estate. Eastern Economic Journal 34 (Winter), 1-13.

Timmerman, A., 1996. Excess volatility and predictability of stock prices in autoregressive dividend models with learning. Review of Economic Studies 63, 523-557.

U.S. Financial Crisis Inquiry Commission, 2011. Final report on the causes of the financial and economic crisis in the United States, Pursuant to Public Law 111-21 (January).

Vissing-Jorgensen, A., 2004. Perspectives on behavioral finance: Does irrationality disappear with wealth? Evidence from expectations and actions. In Gertler, M., Rogoff, K. (Eds.), NBER Macroeconomics Annual 2003.MIT Press, Cambridge, MA, pp. 139-194.

Williams, J.C., 2013. Bubbles tomorrow, yesterday, but never today? Federal Reserve Bank of San Francisco Economic Letter 2013-27 (September 23). 